\title{
Should the Government Provide Insurance for Catastrophes?
}

J. David Cummins

\begin{abstract}
This paper evaluates the need for a government role in insuring natural and man-made catastrophes in the United States. Although insurance markets have been stressed by major natural catastrophes, such as Hurricane Katrina, government involvement in the market for natural catastrophe insurance should be minimized to avoid crowding-out more efficient private market solutions, such as catastrophe bonds. Instead, government should facilitate the development of the private market by reducing regulatory barriers. The National Flood Insurance Program has failed to cover most property owners exposed to floods and is facing severe financial difficulties. The program needs to be drastically revised or replaced by private market alternatives, such as federal "make available" requirements with a federal reinsurance backstop. A federal role may be appropriate to insure against mega-terrorist events. However, any program should be minimally intrusive and carry a positive premium to avoid crowding-out private market alternatives.
\end{abstract}

Federal Reserve Bank of St. Louis Review, July/August 2006, 88(4), pp. 337-79.

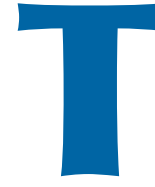

he frequency and severity of natural and man-made catastrophes have increased significantly in recent years. Natural catastrophes include events such as hurricanes, earthquakes, floods, and tsunamis; and man-made disasters include oil platform explosions, aviation disasters, and terrorism. As shown in more detail below, prior to 1986, the number of catastrophes rarely reached 150 per year; but since 1993, there have been at least 270 catastrophes per year. ${ }^{1}$ Of the 40 most costly disasters since 1970, 34 have occurred since 1990 and 15 have occurred since 2000.

1 These figures are from Swiss Re (2006). Swiss Re defines a catastrophe as an event that causes a specified amount of monetary loss or loss of life above a certain threshold: In 2005, the monetary threshold for an event to be defined as a catastrophe is $\$ 77.5$ million and the fatality threshold is 20 . The monetary threshold is adjusted over time so that the catastrophe count is consistent across years. Loss statistics are in terms of insured losses. Total losses, including uninsured losses and infrastructure, would be much larger.
Hurricane Katrina, which made landfall on September 8, 2005, is the most costly catastrophic event in history, with projected insured losses in the range of $\$ 40$ to $\$ 60$ billion. The most costly prior natural catastrophe was Hurricane Andrew in 1992, which cost insurers $\$ 22.3$ billion. The most costly man-made disaster was the September 11, 2001, terrorist attack on the World Trade Center (WTC) in New York, which resulted in about $\$ 40$ billion in insured losses.

The increasing costs of catastrophes have significantly stressed insurance markets. Insurance works best for high-frequency, low-severity events, which are statistically independent and have probability distributions that are reasonably stationary over time. Catastrophic events, and particularly mega-catastrophes such as Katrina and the WTC terrorist attack, violate to some degree nearly all of the standard conditions for insurability. These are low-frequency, high-

J. David Cummins is the Harry J. Loman Professor of Insurance and Risk Management at the Wharton School of the University of Pennsylvania. The author acknowledges helpful comments and suggestions from William R. Emmons, Scott E. Harrington, Dwight Jaffee, Howard Kunreuther, Christopher M. Lewis, and Erwann Michel-Kerjan.

(C) 2006, The Federal Reserve Bank of St. Louis. Articles may be reprinted, reproduced, published, distributed, displayed, and transmitted in their entirety if copyright notice, author name(s), and full citation are included. Abstracts, synopses, and other derivative works may be made only with prior written permission of the Federal Reserve Bank of St. Louis. 


\section{Cummins}

severity events that violate statistical independence by affecting many insured exposures at one time. Although considerable progress has been made in modeling natural catastrophes, conventional methods are much less effective in evaluating losses from terrorism, given that terrorists are continually modifying their strategies and tactics.

Insurance markets tend to respond adversely to mega-catastrophes. They respond to large events, particularly those that cause them to reevaluate their estimates of the probability and severity of loss, by restricting the supply of insurance and raising the price of the limited coverage that is made available. This occurred, for example, following Hurricane Andrew in 1992 and the Northridge earthquake in 1994 and occurred again following the WTC terrorist attack. Because insurance plays an important role in the economy, instability in the availability and price of coverage generally leads to pressure for government intervention in insurance markets. State governments intervened in Florida and California following Andrew and Northridge, and the widespread availability of windstorm coverage in Florida and earthquake coverage in California seems to be largely attributable to government intervention. The federal government has provided subsidized flood insurance since 1968 and entered the market for terrorism insurance as reinsurer of last resort through the Terrorism Risk Insurance Act of 2002 (TRIA). Governments in several other industrialized nations, including France, Germany, Spain, and the United Kingdom, also have intervened in catastrophe insurance markets.

The objective of this paper is to evaluate the appropriateness of government intervention in catastrophe insurance markets with a particular focus on mega-catastrophes, both natural and manmade. The paper begins with a statistical overview of the recent history of catastrophes and then turns to a discussion of the insurability of such events through the private sector, considering the theoretical criteria usually associated with insurable events. The resources of the U.S. insurance industry and the global reinsurance industry are then evaluated to provide perspective on the insurability of large catastrophes. The last major section of the paper evaluates potential public and private sector solutions to the catastrophe insurance problem, considering alternative risk financing mechanisms such as catastrophe (CAT) bonds as well as the most promising models for government involvement. The discussion includes an evaluation of the effectiveness of TRIA and the likely effect of sun-setting TRIA on the market for terrorism insurance.

\section{CATASTROPHES: THE RECENT HISTORY}

The number of natural and man-made catastrophes since 1970 are shown in Figure 1. The figure indicates a clear upward trend in the number of catastrophes; and a linear trend line fitted to the total number of catastrophes has an adjusted $\mathrm{R}^{2}$ of 0.87 . There seems to be a pronounced shift in the data approximately in 1988 and another shift in 1994. Although scientists have not reached consensus on whether the frequency of natural catastrophes such as hurricanes has been increasing, the major reason for the increasing number of catastrophes is the accumulation of property values in disaster-prone areas such as California, Florida, the Gulf Coast, and, increasingly, Asia.

The value of insured catastrophe losses from natural and man-made events, adjusted to 2005 price levels, is shown in Figure 2. Because catastrophic events also cause significant losses to uninsured property, such as highways, sewer systems, and other infrastructure components, the total value of losses from such events is higher than Figure 2 suggests. However, the insured losses are relevant in evaluating the insurability of such events. Figure 2 shows that, except for the WTC event in 2001, natural disasters cause more insured losses than man-made events. However, the WTC event illustrates that terrorism has added a significant source of volatility that was not previously present. The severity data also show a shift in the late 1980s/early 1990s. Prior to 1987 , total insured catastrophe losses never exceeded $\$ 10$ billion per year; but beginning in 1987, losses have exceeded $\$ 10$ billion in every year and have exceeded $\$ 20$ billion in 11 of 19 years. Following 
Figure 1

Number of Catastrophes, 1970-2005

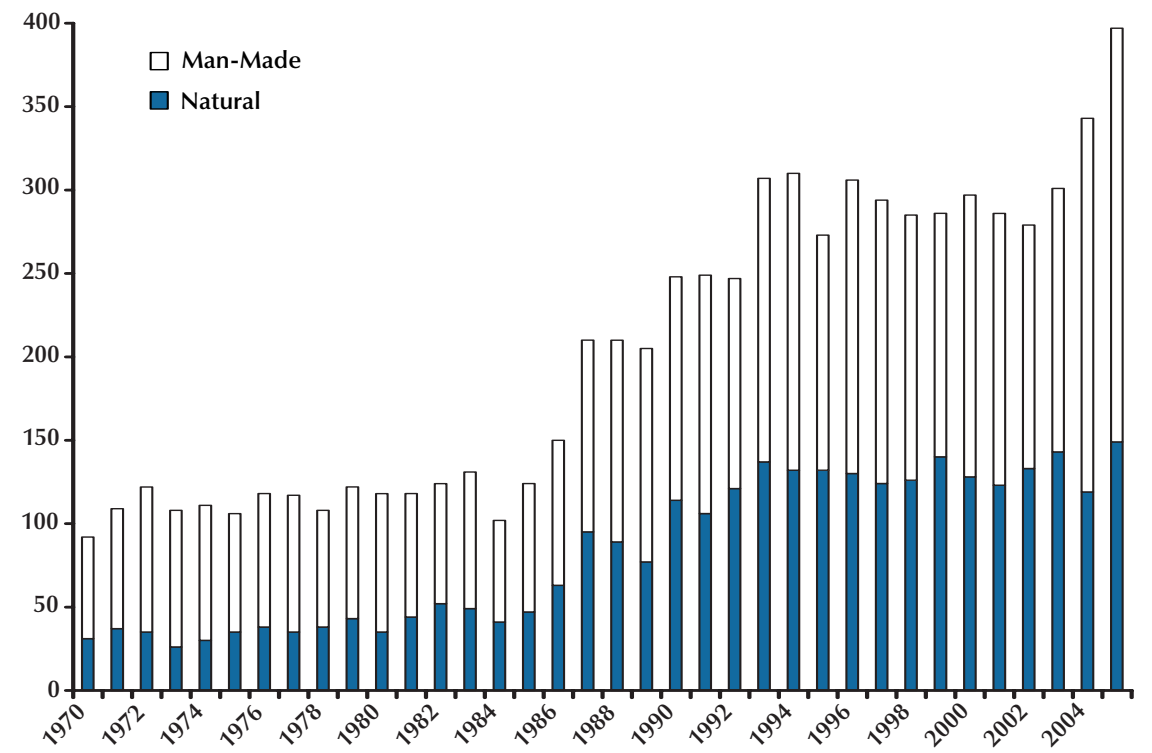

SOURCE: Swiss Re (2006).

Figure 2

Worldwide Insured Catastrophe Losses, 1970-2005

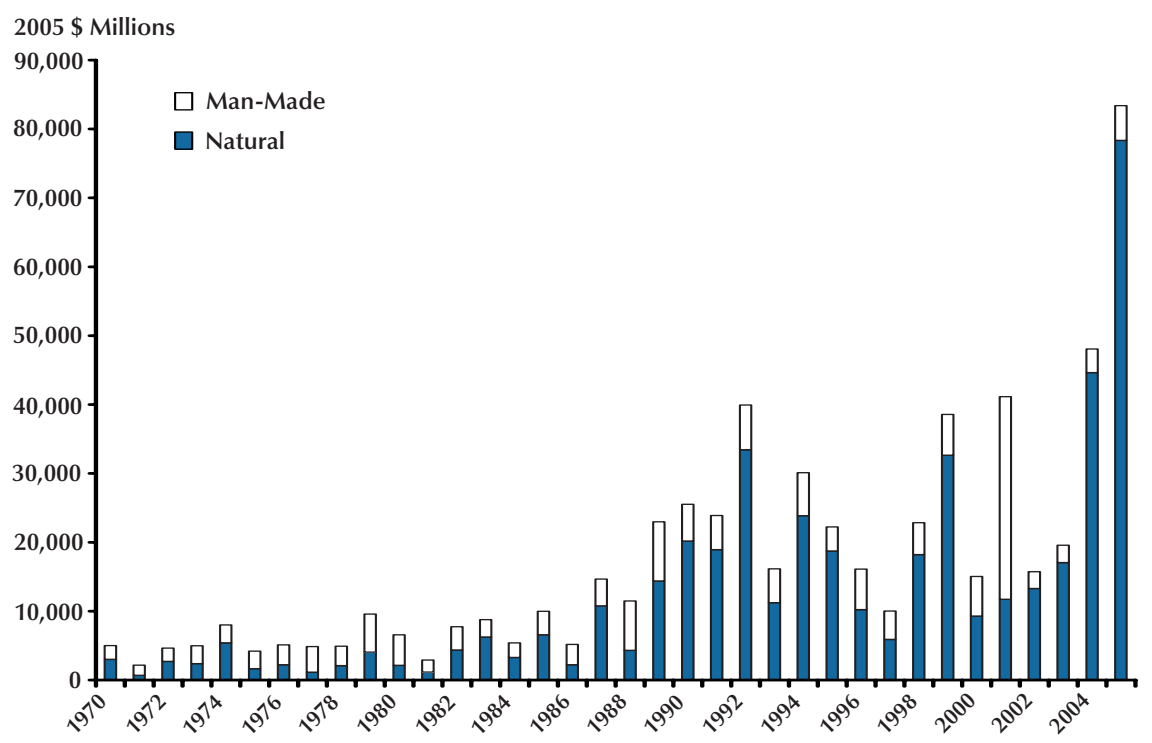




\section{Cummins}

Table 1

Top 40 Insured Catastrophe Losses: 1970-2005

\section{Insured loss ${ }^{1}$}

(2005 \$ millions) Victims ${ }^{2} \quad$ Date (start)

Event

Country/Area

\begin{tabular}{|c|c|c|c|c|}
\hline 45,000 & 1,326 & $8 / 24 / 2005$ & Hurricane Katrina & U.S. Gulf of Mexico, Bahamas \\
\hline 22,274 & 43 & 8/23/1992 & Hurricane Andrew & U.S., Bahamas \\
\hline 20,716 & 2,982 & $9 / 11 / 2001$ & Terrorist attacks on WTC, Pentagon & U.S. \\
\hline 18,450 & 61 & 1/17/1994 & Northridge earthquake (M 6.6) & U.S. \\
\hline 11,684 & 124 & 9/2/2004 & Hurricane Ivan: damage to oil rigs & U.S., Caribbean \\
\hline 10,000 & 34 & 9/20/2005 & Hurricane Rita: floods, damage to oil rigs & U.S.. Gulf of Mexico, Cuba \\
\hline 10,000 & 35 & 10/16/2005 & Hurricane Wilma & U.S., Caribbean \\
\hline 8,272 & 24 & $8 / 11 / 2004$ & Hurricane Charley & U.S., Caribbean \\
\hline 8,097 & 51 & 9/27/1991 & Typhoon Mireille/No 19 & Japan \\
\hline 6,864 & 95 & $1 / 25 / 1990$ & Winterstorm Daria & France, U.K. et al. \\
\hline 6,802 & 110 & $12 / 25 / 1999$ & Winterstorm Lothar & France, Switzerland et al. \\
\hline 6,610 & 71 & 9/15/1989 & Hurricane Hugo & Puerto Rico, U.S. \\
\hline 5,170 & 38 & $8 / 26 / 2004$ & Hurricane Frances & U.S., Bahamas \\
\hline 5,157 & 22 & 10/15/1987 & Storm and floods & France, U.K. et al. \\
\hline 4,770 & 64 & $2 / 25 / 1990$ & Winterstorm Vivian & Europe \\
\hline 4,737 & 26 & 9/22/1999 & Typhoon Bart/No 18 & Japan \\
\hline 4,230 & 600 & 9/20/1998 & Hurricane Georges & U.S., Caribbean \\
\hline 4,136 & 3,034 & 9/13/2004 & Hurricane Jeanne: floods, landslides & U.S., Haiti \\
\hline 3,707 & 45 & 9/6/2004 & Typhoon Songda/No 18 & Japan, South Korea \\
\hline 3,475 & 41 & $6 / 5 / 2001$ & Tropical Storm Allison & U.S. \\
\hline 3,403 & 45 & $5 / 2 / 2003$ & Thunderstorms, tornados, hail & U.S. \\
\hline 3,304 & 167 & 7/6/1988 & Explosion on platform Piper Alpha & U.K. \\
\hline 3,169 & 6,425 & 1/17/1995 & Great Hanshin earthquake ( $M 7.2$ ), Kobe & Japan \\
\hline 2,814 & 45 & $12 / 27 / 1999$ & Winterstorm Martin & Spain, France, Switzerland \\
\hline 2,768 & 70 & 9/10/1999 & Hurricane Floyd: floods & U.S., Bahamas et al. \\
\hline 2,692 & 59 & 10/1/1995 & Hurricane Opal & U.S., Mexico \\
\hline 2,621 & 38 & 8/6/2002 & Severe floods & Europe \\
\hline 2,438 & 26 & 10/20/1991 & Forest fires affecting urban areas, drought & U.S. \\
\hline 2,427 & 0 & $4 / 6 / 2001$ & Hail, floods, and tornados & U.S. \\
\hline 2,366 & 246 & 3/10/1993 & Blizzard and tornados & U.S., Mexico, Canada \\
\hline 2,233 & 20 & 12/3/1999 & Winterstorm Anatol & Denmark, Sweden, U.K. \\
\hline 2,227 & 4 & 9/11/1992 & Hurricane Iniki & U.S., N. Pacific Ocean \\
\hline 2,088 & 23 & 10/23/1989 & Explosion in a petrochemical plant & U.S. \\
\hline 2,068 & 220,000 & $12 / 26 / 2004$ & Seaquake (MW 9.0): tsunamis & Indonesia, Thailand \\
\hline 2,024 & 0 & 8/29/1979 & Hurricane Frederic & U.S. \\
\hline 1,993 & 39 & 9/5/1996 & Hurricane Fran & U.S. \\
\hline 1,981 & 2,000 & 9/18/1974 & Tropical Cyclone Fifi & Honduras \\
\hline 1,947 & 100 & $7 / 4 / 1997$ & Floods after heavy rain & Poland, Czech Republic et al. \\
\hline 1,923 & 116 & 9/3/1995 & Hurricane Luis & Caribbean \\
\hline 1,887 & 18 & 8/1/2005 & Winterstorm Erwin & Denmark, Sweden, U.K. \\
\hline
\end{tabular}

NOTE: ${ }^{1}$ Property and business interruption, excluding liability and life insurance losses. ${ }^{2}$ Dead and missing: Figures are approximate and from various sources.

SOURCE: Swiss Re (2006). 


\section{Figure 3}

\section{Catastrophe Losses Relative to World and U.S. GDP}

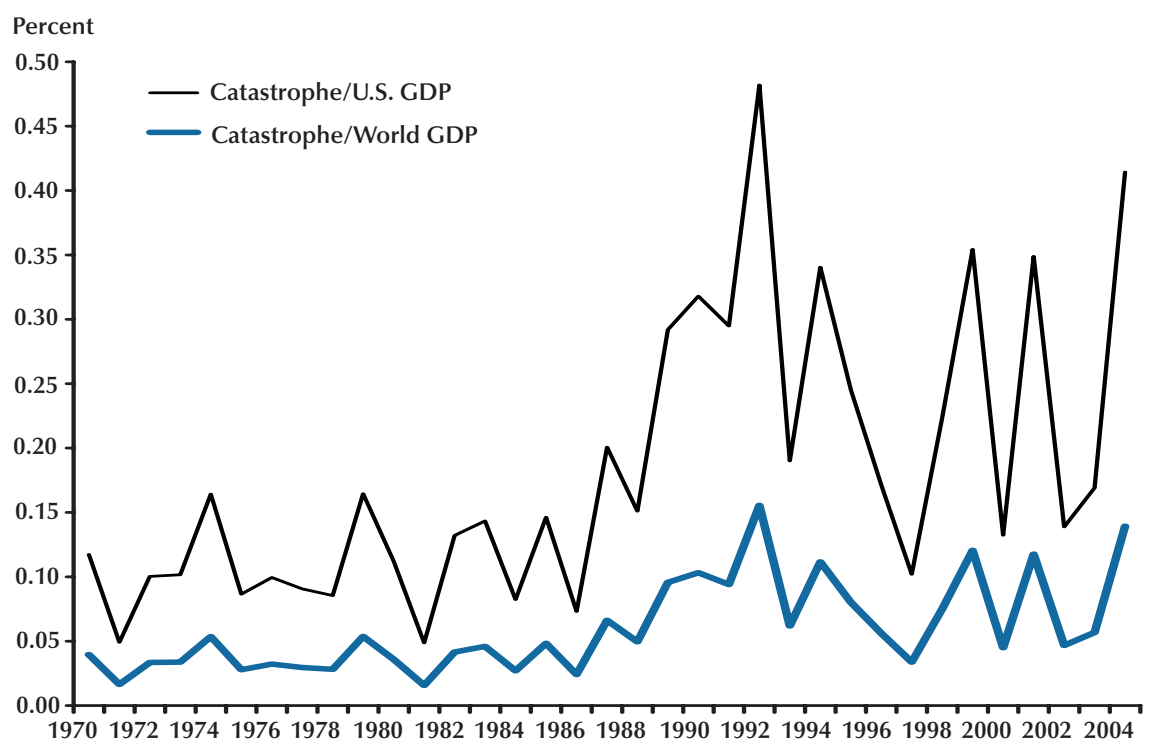

SOURCE: Catastrophe losses: Swiss Re (2005a); World GDP: The World Bank; U.S. GDP: U.S. Department of Commerce.

a record-year in 2004, when losses totaled $\$ 48$ billion, losses nearly doubled to $\$ 80$ billion in 2005 with the devastation of hurricanes Katrina, Rita, and Wilma. Katrina in particular not only was an unprecedented natural disaster from an insurance perspective but also raised significant questions about the U.S. system for assessing, mitigating, and financing disasters and disaster relief. $^{2}$

The top 40 insured catastrophe losses since 1970 are shown in Table 1: 34 of the top 40 have occurred since 1990 and 15 have occurred since 2000; 7 of the 10 most costly hurricanes in U.S. history occurred during the 17-month period of August 2004 through October 2005 (Hartwig, 2005). All but 3 of the top 40 losses are from natural catastrophes, and the losses from the WTC terrorist attack are roughly six times the previous largest man-made catastrophe, which was the explosion and fire on the Piper Alpha oil platform in 1988.

2 For an excellent analysis of the lessons to be learned from Katrina in terms of disaster assessment, prevention, mitigation, and financing, see Daniels, Kettl, and Kunreuther (2006).
The table also shows that the United States is the primary source of large catastrophe losses worldwide. In 2004, for example, 67.7 percent of worldwide insured catastrophe losses were North American (primarily U.S.) events (Swiss Re, 2005a); and in 2005, the North American total reached 87.1 percent of worldwide losses (Swiss Re, 2006).

Figure 3 places the catastrophe losses in a broader perspective by showing total insured catastrophe losses as percentages of world and U.S. gross domestic product (GDP). In relation to world GDP, catastrophe losses were less than 0.05 of 1 percent until the late 1980s and have fluctuated around 0.10 of 1 percent in more recent years. In relation to U.S. GDP, catastrophe losses were less than 0.20 of 1 percent until the late 1980s and have been above 0.30 of 1 percent in several years since 1990. There is a significant upward trend in both series, with adjusted $\mathrm{R}^{2}$ values of around 0.35 in linear time trend regressions. Figure 3 suggests that catastrophe losses are large and volatile from the perspective of the insurance 


\section{Cummins}

industry but are more manageable from an economywide or societal perspective.

\section{THE INSURABILITY OF CATASTROPHE LOSSES}

This section evaluates the insurability of catastrophe losses. The section begins with a discussion of the theoretical criteria for insurability and an analysis of the differences between natural and unintentional man-made catastrophes on the one hand and intentional events such as terrorism on the other. The section concludes with an evaluation of the resources of the insurance and global reinsurance industries and an economic evaluation of the insurance crises and cycles.

\section{Criteria for Insurability}

Individuals are averse to pure risk and are willing to pay amounts greater than the expected value of losses in return for transferring risk to an insurer. ${ }^{3}$ Most businesses also have a demand for risk transfer and, like consumers, are willing to pay more than the expected loss to transfer risk to another party. The amounts greater than expected losses that individuals and businesses are willing to pay for risk transfer give rise to gains from trade that have motivated the development of the insurance and reinsurance industries.

The role of the insurer is to assume risk from individuals and businesses and to diversify risk by pooling the losses of many policyholders. The statistical foundation of insurance is the law of large numbers. The role of insurers can be elucidated by specifying a simple statistical model of a risk pool. Let $X_{1}, \ldots, X_{N}$ be a random sample from a probability distribution with finite means $\mu_{i}$ and variances $\sigma_{i}^{2}$, where $X_{i}$ represents the loss suffered by the ith policyholder in a risk pool. It is helpful to assume that the $X_{i}$ are normally distributed, although they are not necessarily independent. ${ }^{4}$ The law of large numbers then states that

3 This discussion is based in part on analysis in Cummins and Weiss (2000).

4 The law of large numbers does not require normality. Normality is assumed here because it provides a convenient explanation of the role of equity capital in the insurance market.

$$
\lim _{N \rightarrow \infty} \operatorname{Pr}[\mid \bar{X}-\bar{\mu}<\varepsilon]=1
$$

where

$$
\bar{X}=\sum_{i} \frac{X_{i}}{N}
$$

is the sample mean based on a realization of losses from the $N$ policies,

$$
\bar{\mu}=\sum_{i} \frac{\mu_{i}}{N}
$$

is the average mean loss, and $\varepsilon$ is an arbitrarily small number. Intuitively, the law of large numbers says that the sample mean becomes arbitrarily close to the population mean as the sample size increases. Thus, the expected loss is highly predictable in a sufficiently large sample.

With the normality assumption, we can use the central limit theorem to specify the amount of equity capital needed by the insurer. We assume that insurers hold equity capital to achieve a specified insolvency probability, $\varepsilon$. Insolvency probabilities are not driven to zero because holding capital in an insurance company is costly due to corporate income taxation, agency costs, regulatory costs, accounting rules, and other factors (Jaffee and Russell, 1997). The central limit theorem specifies that the following variable approaches normality as the sample size increases:

$$
z=\frac{\sum_{i=1}^{N} X_{i}-N \bar{\mu}}{\sigma_{N}} .
$$

The parameter $\sigma_{N}^{2}$, the insurer's loss portfolio variance, is defined as

$$
\sigma_{N}^{2}=\sum_{i=1}^{N} \sigma_{i}^{2}+2 \sum_{j=2}^{N} \sum_{i=1}^{j-1} \sigma_{i j}
$$

where $\sigma_{i j}=\operatorname{Cov}\left(X_{i}, X_{j}\right)$. The normal distribution implies that

$$
\operatorname{Pr}\left[\frac{\sum_{i=1}^{N} X_{i}-N \bar{\mu}}{\sigma_{N}}<z_{\varepsilon}\right]=1-\varepsilon,
$$

where $z$ is the standard normal variate and $z_{\varepsilon}$ is the value from the standard normal distribution 
such that $\operatorname{Pr}\left[z<z_{\varepsilon}\right]=1-\varepsilon$. The amount of equity capital needed to achieve a target insolvency probability of $\varepsilon$ is $z_{\varepsilon} \sigma_{N}$, assuming that policyholder premiums cover the expected loss, $N \bar{\mu}$.

The standard normal result for equity capital can be used to illustrate the effects of pooling. Assume that the $N$ risks in the portfolio are statistically independent, so that all of the covariances in equation (3) are zero. Then equity capital per policy is

$$
\frac{z_{\varepsilon} \sigma_{N}}{N}=\frac{z_{\varepsilon} \sqrt{\bar{\sigma}^{2}}}{\sqrt{N}}
$$

where

$$
\bar{\sigma}^{2}=\sum_{i=1}^{N} \sigma_{i}^{2} / N
$$

is the average variance. Thus, equity capital per policy goes to zero as $N$ goes to infinity, implying that large insurers insuring independent risks with reasonably small variances can charge a premium very close to the expected value of loss. ${ }^{5}$ I call insurance markets with independent risks, moderate standard deviations per risk, and large $N$ locally insurable. The U.S. market for personal automobile insurance is an example of a locally insurable market.

The motivation for reinsurance becomes apparent when we relax the assumptions under which risks are locally insurable. For example, reinsurance markets are likely to be required for risks with large variances and small $N$, even if we maintain for the moment the assumption that risks are statistically independent. Further motivation for the development of reinsurance markets is provided by relaxing the assumption that risks are independent. If risks are dependent, the amount of equity capital needed per risk to achieve a given insolvency target becomes

$$
\frac{z_{\varepsilon} \sigma_{N}}{N}=\frac{\sqrt{N \bar{\sigma}^{2}+N(N-1) \bar{\sigma}_{i j}}}{N},
$$

\footnotetext{
5 Notice, however, that this does not imply that large insurers need no equity capital. The equity capital needed to achieve a target ruin probability of $\varepsilon$ with independent risks is$$
z_{\varepsilon} \sqrt{N \bar{\sigma}^{2}},
$$

which approaches infinity as $\mathrm{N}$ goes to infinity.
}

where $\bar{\sigma}_{i j}$ is the the average covariance among the $N$ risks. It is easy to see that the amount of equity capital needed per policy approaches

$$
z_{\varepsilon} \sqrt{\bar{\sigma}_{i j}} \text { as } N \rightarrow \infty \text {. }
$$

If the average covariance is small, the risks may still be locally insurable, but the market outcome is inefficient in that the risk charge per policy has not been reduced to approximately zero.

However, risks that are locally dependent may be globally independent, for example, the risk of tornadoes in the American Midwest versus Australia. This provides an economic motivation for reinsurance markets because insurers can reduce their prices relative to competitors by ceding the covariance risk to a reinsurer who can pool the risk with independent risks from other regions of the world. We call risks that are globally diversifiable through reinsurance globally insurable.

Implicit in this discussion are some additional criteria for insurability. One important criterion is that $N$ be sufficiently large for the law of large numbers to operate such that the insurer achieves effective diversification either locally or globally. Also important is that $\bar{\sigma}^{2}$ and $\bar{\sigma}_{i j}$ (if the latter is non-zero) be sufficiently "small"-again to ensure that effective diversification takes place. If $N$ is too small or $\bar{\sigma}^{2}$ and $\bar{\sigma}_{i j}$ too large, then the amount of capital the insurer must hold to achieve a sufficiently small insolvency probability may be too large for insurance to be feasible. Essentially, the cost of capital may push the price of insurance above the level that buyers are willing to pay for coverage, eliminating the gains from trade.

Another important implicit assumption is that sufficient data are available to enable the insurer to estimate the parameters of the loss distribution, $\mu_{i}$ and $\sigma_{i}^{2}$, and the covariances among risks, $\sigma_{i j}$, if the risks are not independent. This is a non-trivial requirement, given that real-world risks are not identically distributed such that applicants for insurance have heterogeneous parameters. It is well-known that insurance markets can break down as a result of adverse selection if the insurer is not able to discriminate among risks (Rothschild and Stiglitz, 1976). A final requirement is that the 


\section{Cummins}

loss distribution should be reasonably stationary so that parameters estimated from past data are reasonably good predictors of future loss distributions. If the loss distribution shifts significantly during short periods of time, such as one or two years, the insurer will be unable to estimate premiums or the required amount of equity capital and insurability will break down.

The violation of any of the principal insurability conditions may create situations where risks are neither locally nor globally insurable. However, if other conditions are satisfied, such risks may be globally diversifiable through capital markets. Consider the example of events with low frequency and very high severity, where the covariances among the individual risks making up a portfolio are also relatively high. Examples of such risks are unusually severe hurricanes and earthquakes striking geographical regions with high concentrations of property values. For example, modelers have estimated that a $\$ 100$ billion event in Florida or California has a probability of occurrence in the range of 1 in 100 (i.e., a "return period" of 100 years). The capacity of the insurance and reinsurance industries may be inadequate to insure such events.

However, events of this magnitude are small relative to the market capitalization of securities markets. Thus, by introducing securitized financial instruments representing insurance risk, catastrophic events in the $\$ 100$ billion range are diversifiable across the financial markets, even though they may not be diversifiable in global insurance and reinsurance markets. Such events also have relatively low correlations with securities returns, effectively providing an attractive source of diversification for investors. Securitization extends the scope of diversification from insurance and reinsurance markets to the entire securities market, thus breaking down the problem of small $N$, large $\sigma$ 's, and intra-insurance market correlations, in much the same way as reinsurance can reduce or eliminate the problem of non-insurability on the local level. Diversifying insurance-linked risk across the securities market provides the motivation for CAT bonds, which are discussed in more detail below.
The final category of risks consists of events that are so severe that they may not be globally diversifiable even through securities markets. It has been estimated that a severe earthquake in Tokyo could cause losses in the range of $\$ 2.1$ to $\$ 3.3$ trillion, constituting from 44 to 70 percent of the GDP of Japan (Risk Management Solutions, 1995). Although it is possible that global securities markets could absorb a significant fraction of such a loss, the full loss is unlikely to be fully diversifiable. I call such events cataclysmic, or globally undiversifiable.

Losses from mega-terrorism events may also fall into the globally undiversifiable category. Such losses are similar in many ways to losses arising from war, which are generally not amenable to private market insurance or diversification solutions. In addition to sharing the problems of small $N$ and large $\mu$ and $\sigma$ with mega-losses from natural hazards, terrorism losses also pose the problem of being very difficult to estimate. Modelers have made significant progress in estimating losses from natural hazards. Modeling firms such as Applied Insurance Research, Equicat, and Risk Management Solutions have developed highly sophisticated models of natural hazard losses based on both statistical data and scientific models of hurricanes and earthquakes. The models have been parameterized using detailed mappings of exposures across the United States and in other major countries. The hurricane and earthquake perils are sufficiently stable in a statistical sense to give modelers confidence in their ability to predict the frequency and severity of future events and to enable insurers to use the models to manage their exposure to catastrophe risk.

Terrorism events are inherently much more difficult to estimate than natural catastrophes. Few statistical data exist that can be used to estimate the parameters of loss distributions. Data on terrorism activities obtained by the government are confidential for national security reasons and hence not available to insurers to assist in estimating premiums and loss exposure. Moreover, terrorists constantly change strategies and tactics, making any predictions from past data inherently unreliable. Terrorists are likely to engage in "target substitution," shifting their attention to targets that 
receive the least amount of security. Although some progress has been made in modeling the severity of mega-terrorism events, based on scientific knowledge about the effects of nuclear and conventional explosions and biological and radiation hazards, little information exists that can assist insurers in estimating the probability of terrorism losses. The possibility that terrorists could use weapons of mass destruction raises potential losses from mega-terrorism to levels far exceeding the potential losses from even the largest natural catastrophes.

Another major difference between terrorism and other types of catastrophes is that the frequency and severity of terrorist attacks are significantly affected by U.S. governmental policy. U.S. foreign policy directly impacts the motivation and likelihood of terrorist attacks from different militant factions. U.S. domestic policy and the success of government homeland security programs also affect the mitigation of terrorist attacksboth in preventing such attacks and mitigating the magnitude of any attack that does occur. Moreover, much of the information required to predict terrorist events is likely to remain highly classified and unavailable to those outside of agencies such as the FBI and CIA. In fact, one of the arguments proffered in support of a federal role in the provision of terrorism insurance was that terrorism events represent a negative externality of the national security policies of the sovereign government. Thus, there are significant reasons to believe that government may have to be the insurer of last resort, at least for mega-terrorism events.

\section{Insurance Industry Resources, Cycles, and Crises}

As mentioned, insurance works best for highfrequency, low-severity, relatively stationary, relatively independent events with good data and moderate loss volatilities. ${ }^{6}$ For such events, insurers can accurately estimate premiums and the equity capital needed to reduce insolvency probabilities to acceptable levels, and the amount of ${ }^{6}$ Some additional criteria for insurability are discussed in Swiss Re
(2005b). required equity does not lead to excessive prices. Even for larger, less-frequent, more-risky events such as commercial liability lawsuits, insurance can also be effective most of the time. However, there are significant questions about the ability of the insurance industry to deal with the largest catastrophic events. For various reasons, it is infeasible and inefficient for the industry to hold sufficient capital to finance losses arising from very-high-severity, low-frequency events (Jaffee and Russell, 1997). This section provides an overview of the resources of the U.S. propertycasualty insurance industry and the global reinsurance industry to gauge the industry's capability to sustain losses from mega-catastrophes.

The total resources of the U.S. propertycasualty insurance industry are shown in Figure 4. In 2004, the industry held about $\$ 400$ billion in equity capital and collected premiums of about $\$ 440$ billion. Although this might seem to be more than enough to withstand a catastrophic loss of $\$ 100$ billion, in fact, most of the premiums represent expected loss payments for high-frequency lines such as automobile insurance and workers compensation insurance. The premiums for homeowners insurance, the line most exposed to natural disasters, are only about 12 percent of the total. Moreover, the $\$ 400$ billion in equity capital represents the total amount held by insurers writing all lines of business in all states. Only a fraction of the total would be available to pay catastrophe losses in high-exposure states such as California and Florida because insurers not writing policies with catastrophe exposure in those states could not be called upon to pay claims.

Cummins, Doherty, and Lo (2002) investigated the capacity of the U.S. property-casualty insurance industry to respond to large catastrophic events during the late 1990s. They considered the aggregate resources of the industry nationwide and also the resources of insurers writing policies in the catastrophe-prone state of Florida as well as the correlation of losses among companies, another factor in determining the capacity to respond to catastrophic events. The results indicated that the industry could pay more than 90 percent of the losses from a $\$ 100$ billion-loss event. However, a loss of this magnitude would have caused the failure of approximate 140 insur- 


\section{Figure 4}

\section{U.S. Property-Casualty Insurance Industry: Total Resources}

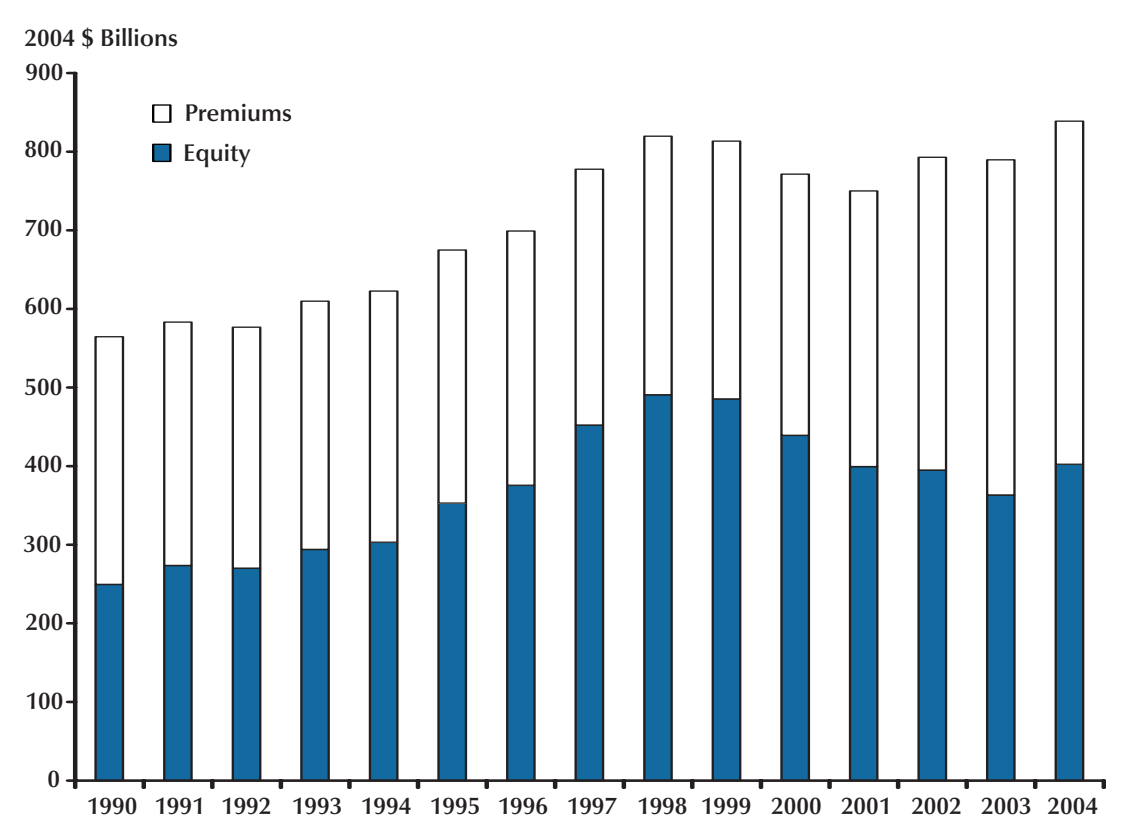

SOURCE: A.M. Best Company, Best's Aggregate and Averages (various years). Resources expressed in real 2004 U.S. dollars using the consumer price index.

ance companies. This would be by far the largest failure rate in the post-1900 history of the U.S. property-casualty industry and would significantly destabilize insurance markets.

The aggregate equity capital of the global reinsurance industry is shown in Figure 5. The figure indicates that equity capital increased significantly from 1990 to 2003, from about $\$ 250$ billion to about $\$ 340$ billion, and increased more modestly in 2004 to $\$ 377$ billion. ${ }^{7}$ The premiums of global reinsurers were about $\$ 167$ billion in 2004 (Standard and Poor's, 2005). ${ }^{8}$ However, most

\footnotetext{
7 The capital numbers somewhat overstate the capacity of global reinsurers, however, because they represent the total equity capital of companies writing reinsurance. There are several large companies participating in this market, such as ING, AIG, and AXA, that also write significant amounts of coverage in the primary insurance market. Hence, their equity capital supports both their primary insurance and reinsurance obligations. In addition, as in the U.S. insurance market, most of the equity capital is committed to support coverage in high-frequency lines of business.

8 Unlike the equity capital figures, the premium numbers are indica-
} tive of business written in the reinsurance market. of the premiums are for high-frequency lines of business. To put the equity capital totals in perspective, Figure 5 also shows the worldwide catastrophe losses from Swiss Re (2005a) as a ratio to the equity capital of global reinsurers. Catastrophe losses can amount to a significant proportion of equity, exceeding 15 percent in 1999 and 2001 and reaching 13 percent in 2004.

Insurance markets are subject to cycles and crises, which can be triggered by shifts in the frequency and severity of losses as well as investment losses. The underwriting cycle refers to the tendency of property-casualty insurance markets to go through alternating phases of "hard" and "soft" markets. In a hard market, the supply of coverage is restricted and prices rise; whereas, in a soft market, coverage supply is plentiful and prices decline. The consensus in the economics literature is that hard and soft markets are driven by capital market and insurance market imperfections such that capital does not flow freely into and out of 


\section{Figure 5}

\section{Global Reinsurers: Aggregate Equity Capital and Catastrophe Losses}

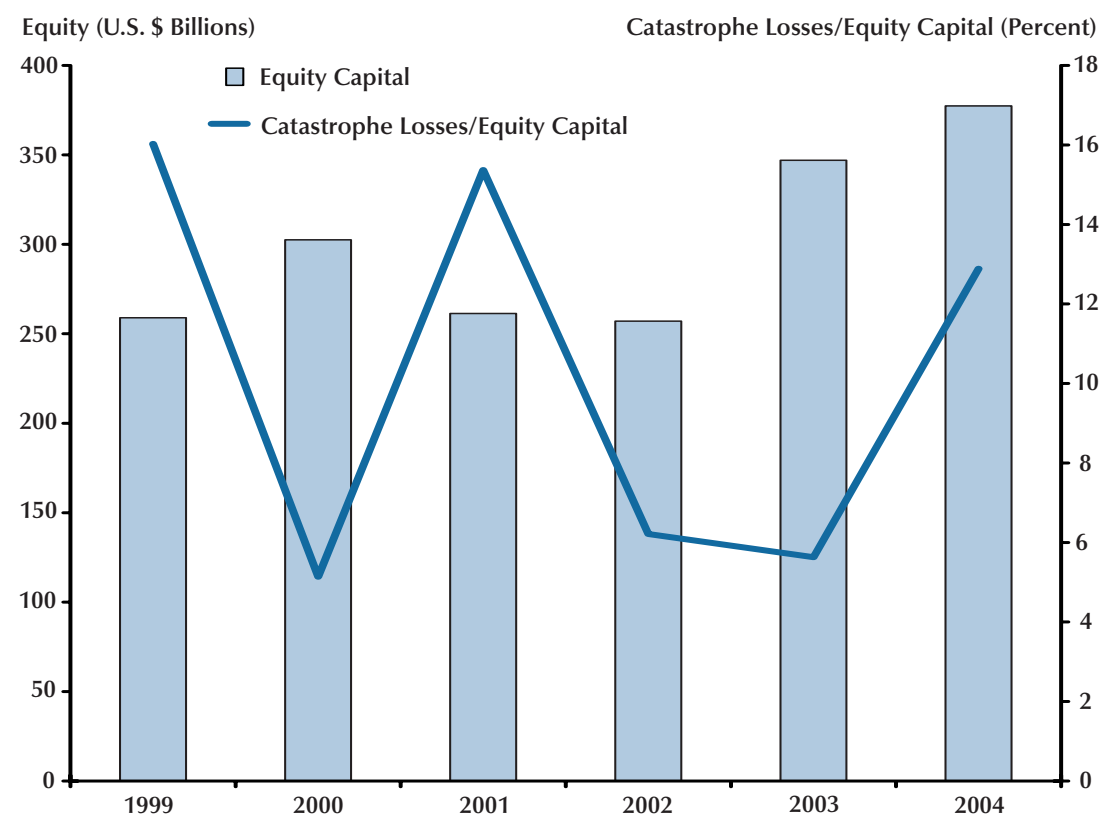

NOTE: Equity is expressed in real 2004 U.S. dollars using the consumer price index.

SOURCE: Standard and Poor's, Global Reinsurance Highlights (various years).

the industry in response to unusual loss events (Winter, 1994; Cummins and Danzon, 1997; and Cummins and Doherty, 2002). Informational asymmetries between capital providers and insurer management about exposure levels and reserve adequacy result in high costs of capital during hard markets, such that capital shortages can develop. Insurers are reluctant to pay out retained earnings during soft markets because of the difficulty of raising capital again when the market enters the next hard-market phase, leading to excess capacity and downward pressure on prices.

Hard markets are usually triggered by capital depletions that result from underwriting or investment losses. The three most prominent hardmarket periods since 1980 resulted from the commercial liability insurance crisis of the 1980s, catastrophe losses from Hurricane Andrew in 1992 and the Northridge earthquake in 1994, and the WTC terrorist attack in 2001. The 1980s liability crisis was triggered by an unexpected increase in the frequency and severity of commercial liability claims, accompanied by a sharp decline in interest rates in the early 1980s, and the catastrophe and terrorist crises were driven by catastrophe losses of unexpected magnitude. Each crisis not only depleted insurer capital but caused insurers to re-evaluate probability of loss distributions and reassess their exposure management and pricing practices.

The U.S. property-casualty insurance underwriting cycle is illustrated in Figure 6. The figure plots two important operating ratios for the industry-the underwriting profit ratio and the overall profit ratio. The underwriting profit ratio is the difference between 100 and the industry combined ratio, which is the sum of the loss ratio (losses incurred divided by premiums) and the expense ratio (operating expenses divided by premiums), expressed as percentages. If the underwriting profit ratio is positive, the industry is collecting 
Figure 6

\section{U.S. Property-Casualty Insurance Industry Underwriting Profit and Overall Profit Ratios}

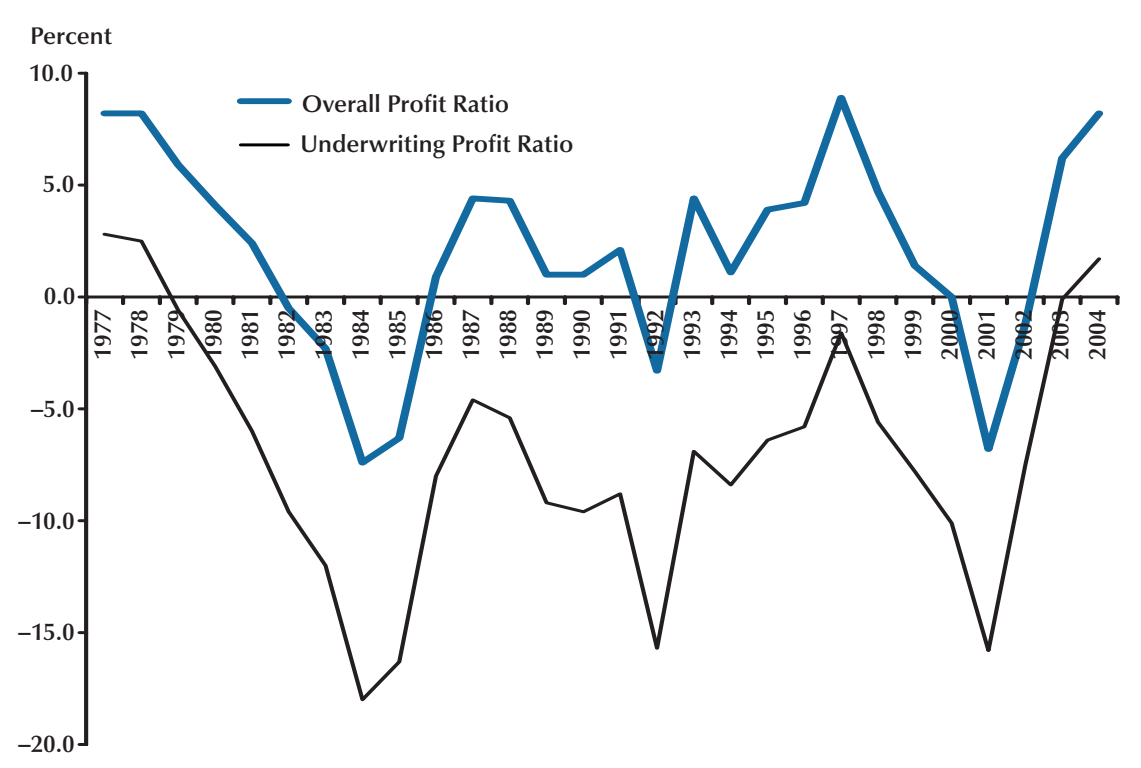

SOURCE: A.M. Best Company, Best's Aggregates and Averages (various years).

more in premiums than it is paying out in losses and expenses-it is incurring an underwriting profit; and if the ratio is negative, the industry is incurring an underwriting loss. The underwriting profit ratio is a useful indicator of underwriting performance, but it is not a very good indicator of overall profitability because it does not consider investment income. The overall profit ratio corrects for investment income by adding the ratio of investment income to premiums to the underwriting profit ratio. If the overall profit ratio is positive, the implication is that insurers are making profits when both underwriting and investment results are considered; and if the overall profit ratio is negative, insurers are realizing overall losses.

Figure 6 reveals the impact of the liability crisis of the mid-1980s and the catastrophe crises of 1992-94 and 2001. The underwriting loss in 1984 was about 18 percent of premiums, and the overall profit ratio indicated a net loss of about 7 percent of premiums in that year after considering investment income. In 1992, the underwriting loss, mainly due to Andrew, was 15 percent and the overall profit ratio showed a loss of about 4 percent of premiums. The underwriting loss due to the WTC attack was also about 15 percent of premiums, and the overall loss was about 6.5 percent. With losses of this magnitude and volatility, it is not surprising that insurers restricted supply and raised prices following these events. ${ }^{9}$

Another indicator of recent underwriting cycle activity in the United States is provided by survey data collected by the Council of Insurance Agents and Brokers. The Council conducts a quarterly survey of its members to determine the changes in commercial lines insurance prices, based on policies renewing in each quarter. The average rate changes from 1999 through 2005 are shown in Figure 7. The figure shows that prices had been increasing significantly even before September

\footnotetext{
${ }^{9}$ It is also noteworthy that the underwriting profit ratio is negative most of the time. This is an expected result in terms of insurance financial pricing theory. Premiums reflect the expected discounted value of claims and operating expenses, whereas losses and expense are reported at undiscounted values. Hence, even under normal circumstances, an underwriting loss is the expected outcome.
} 


\section{Figure 7}

\section{Commercial Property-Casualty Premium Rate Changes by Line}

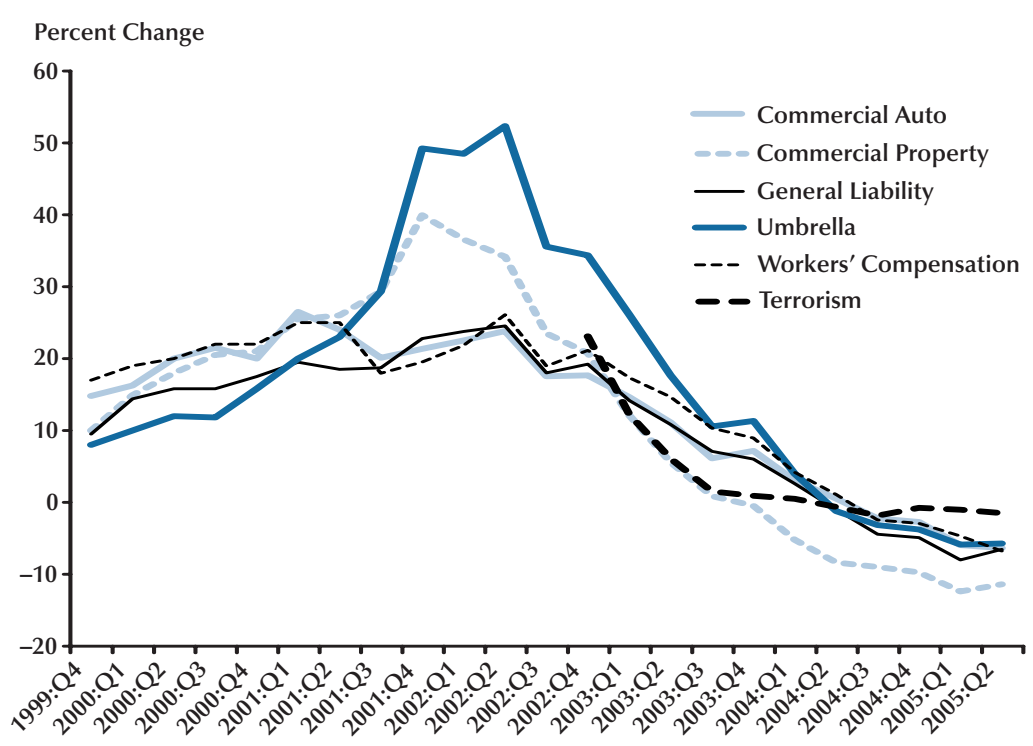

SOURCE: Council of Insurance Agents and Brokers.

of 2001, and the prices in umbrella liability and commercial property insurance spiked after 9/11. However, beginning in early 2002, commercial insurance prices began to decline sharply, reflecting a softening of the market caused by inflows of new capital and improved underwriting profitability.

The underwriting cycle interacts with the level of capitalization in the industry. A relative measure of capitalization is provided by the premiums-to-surplus ratio, the most widely used measure of leverage for this industry. ${ }^{10}$ The premiums-to-surplus ratio since 1980 is graphed in Figure 8 . The ratio was about 1.5 in the early $1980 \mathrm{~s}$ and then declined steadily to less than 0.7 in 1999, before increasing again as a result of the hard market and 9/11 claims in the early 2000s. The sharp decline during the 1990s has been attributed to over-capitalization in the industry as well as the need for additional capital brought about by higher loss volatility, particularly in liability and

${ }^{10}$ Surplus or policyholders' surplus is the industry's terminology for equity capital. property catastrophe insurance (Cummins and Nini, 2002). Deterioration in the premiums-tosurplus ratio is often associated with the onset of a hard-market phase of the cycle.

Because profitability in reinsurance markets mirrors the results in primary insurance markets and because underwriting cycles also exist in most other industrialized countries, the global reinsurance market is also subject to underwriting cycles. ${ }^{11}$ The cycle in the worldwide catastrophe reinsurance market is shown in Figure 9, which plots the rate-on-line index in this market. The rate-on-line is a price measure defined as the premium for a reinsurance policy divided by the maximum possible payout under the policy. The index increased from 100 in 1990 to approximately 375 in 1993, primarily due to Hurricane Andrew. The index then declined steadily until 1999 and increased sharply following the WTC attack and a general hardening of insurance markets into the early 2000s. The decline after

${ }^{11}$ For further discussion of the role of reinsurance in cycles and crises, see Berger, Cummins, and Tennyson (1992). 
Cummings

Figure 8

Property-Casualty Insurance Industry: Premiums-to-Surplus Ratio

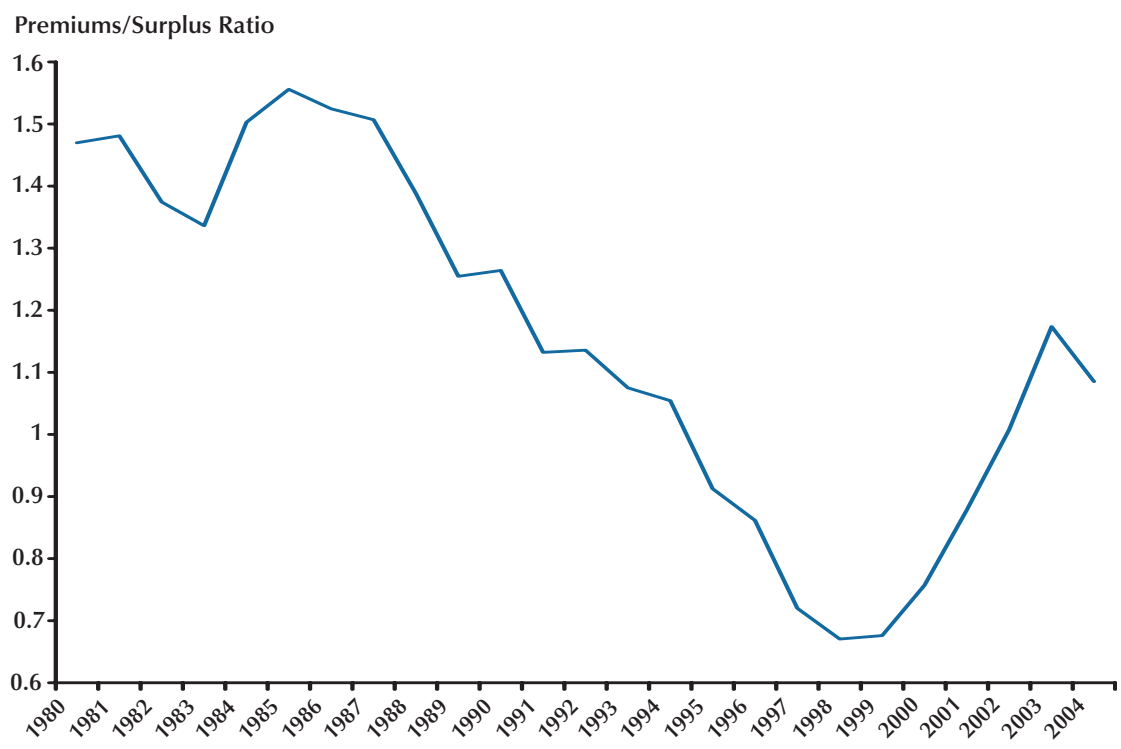

SOURCE: A.M. Best Company, Best's Aggregates and Averages (various years).

Figure 9

World Rate-On-Line Index: Catastrophe Reinsurance

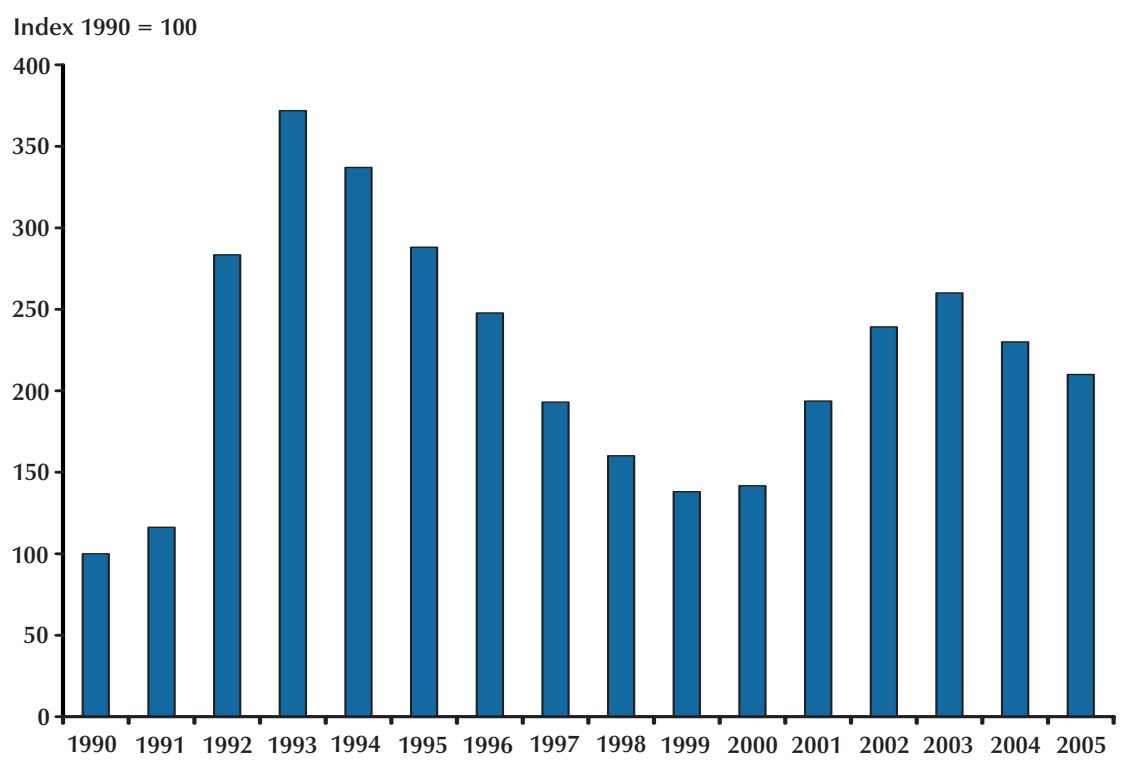

SOURCE: Guy Carpenter (2005).

350

JULY/AUGUST 2006

FEDERAL RESERVE BANK OF ST. LOUIS REVIEW 


\section{Figure 10}

\section{Global Non-Life Reinsurance Industry: Financial Performance}

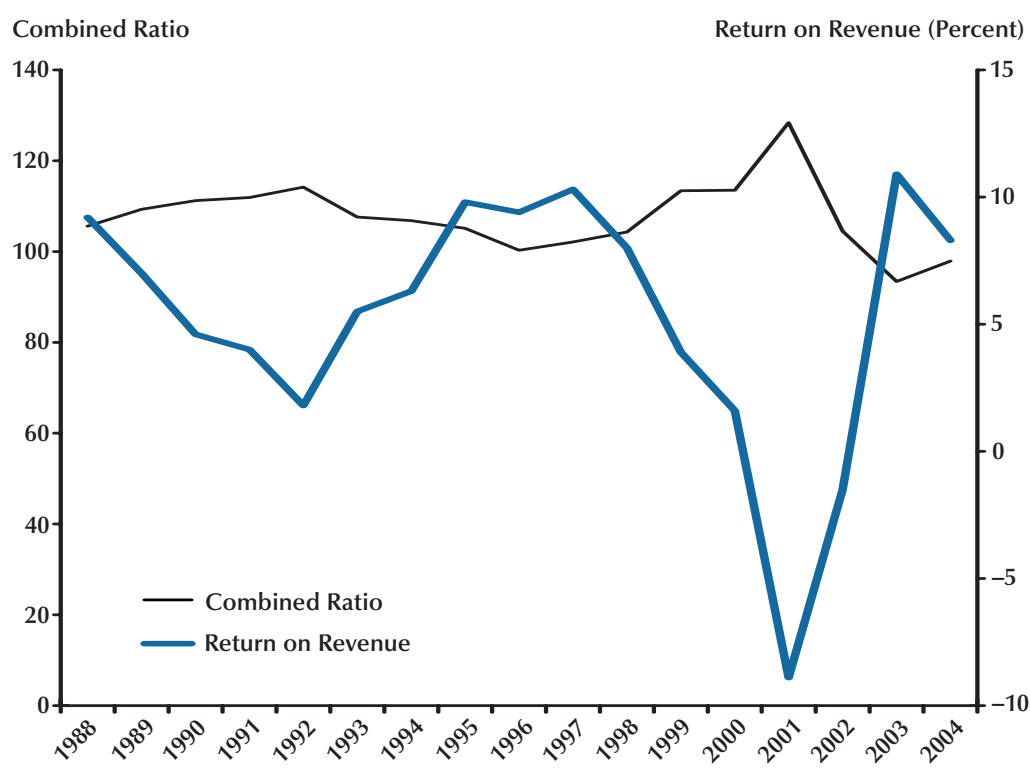

SOURCE: Standard and Poor's, Global Reinsurance Highlights (2005).

Andrew reflected improvements in catastrophe modeling and exposure management in the industry as well as significant inflows of new equity capital, particularly into new and preexisting insurers located in Bermuda.

Further evidence of the reinsurance underwriting cycle is shown in Figure 10, which plots the combined ratio and return-on-revenue ratio for the global non-life reinsurance industry. ${ }^{12}$ The combined ratio spiked at about 115 in 1992 and again at nearly 130 in 2001; and the return on revenue, which also reflects investment earnings, tends to be the reverse mirror image of the combined ratio. The losses incurred during crisis

12 The combined ratio is the sum of the loss ratio (losses and lossadjustment expenses incurred/premiums earned) and the expense ratio (underwriting expenses incurred/premiums written). The ratio is a commonly used measure of underwriting profitability. Return on revenue is analogous but not identical to the overall profit ratio. Return on revenue is defined as pretax operating income/total revenue. Pretax operating income is underwriting profit (or loss) + net investment income + other income. Net realized gains or losses are excluded from pretax income. Total revenue is equal to net premiums earned + net investment income + other income. See Standard and Poor's (2005, p. 47). periods lead reinsurers to raise prices and restrict supply while they recapitalize and reevaluate pricing and exposure management strategies.

The existence of cycles and crises implies that the insurance industry goes through periods when risk-bearing capacity is limited. Although usually triggered by high-volatility lines of business, the effects of a hard market extend to all lines of business including generally predictable lines such as automobile insurance and workers compensation. Thus, capacity shortages can occur even in high-frequency, low-severity lines of insurance, emphasizing the difficulty faced by the industry in consistently providing capacity for low-frequency, high-severity losses.

\section{PUBLIC AND PRIVATE SECTOR SOLUTIONS TO FINANCING CATASTROPHIC RISK}

This section discusses public and private sector solutions to financing the risks of natural 


\section{Cummins}

catastrophes and terrorism, beginning with the securitization of catastrophic risk. Public sector solutions to the catastrophic-risk problem are then discussed, including a review of public sector mechanisms currently in place in the United States and other industrialized nations. The section concludes with an evaluation of TRIA and recommendations regarding the need for governmental involvement in the future.

\section{CAT Bonds}

Following Hurricane Andrew in 1992, efforts began to access securities markets directly as a mechanism for financing future catastrophic events. The first contracts were launched by the Chicago Board of Trade, which introduced catastrophe futures in 1992 and later introduced catastrophe put and call options. The options were based on aggregate catastrophe-loss indices compiled by Property Claims Services, an insurance industry statistical agent. ${ }^{13}$ The contracts were later withdrawn because of lack of trading volume. Insurers had little interest in the contracts for various reasons, including the thinness of the market, possible counterparty risk on the occurrence of a major catastrophe, and the potential for disrupting long-term relationships with reinsurers. Another concern was that the contracts were subject to excessive basis risk; that is, the risk that payoffs under the contracts would be insufficiently correlated with insurer losses. A study by Cummins, Lalonde, and Phillips (2004) confirms that basis risk was a legitimate concern. They found that most insurers could not hedge their exposure to Florida hurricane risk very effectively using a statewide index but that all but the smallest insurers could hedge effectively using four intraFlorida regional indices.

Another early attempt at securitization involved contingent notes known as "Act of God" bonds. In 1995, Nationwide issued $\$ 400$ million in contingent notes through a special trust, Nationwide Contingent Surplus Note Trust. Proceeds from the sale of the bonds were invested in 10-year Treasury securities, and investors were

${ }^{13}$ Contracts were available based on a national index, five regional indices, and three state indices for California, Florida, and Texas. provided with a coupon payment equal to 220 basis points over that of Treasuries. Embedded in these contingent capital notes was a "substitutability” option for Nationwide. Given a prespecified event that depleted Nationwide's equity capital, Nationwide could substitute up to $\$ 400$ million of surplus notes for the Treasuries in the trust at any time during a 10-year period for any "business reason," with the surplus notes carrying a coupon of 9.22 percent. ${ }^{14}$ Although two other insurers issued similar notes, this type of structure did not achieve a significant segregation of Nationwide's liabilities, leaving investors exposed to the general business risk of the insurer and to the risk that Nationwide might default on the notes.

The structure that has achieved a greater degree of success is the CAT bond. CAT bonds were modeled on asset-backed-security transactions that have been executed for a wide variety of financial assets including mortgage loans, automobile loans, aircraft leases, and student loans. The first successful CAT bond was an $\$ 85$ million issue by Hannover Re in 1994 (Swiss Re, 2001). The first CAT bond issued by a nonfinancial firm, occurring in 1999, covered earthquake losses in the Tokyo region for Oriental Land Company, the owner of Tokyo Disneyland.

A CAT bond structure is shown in Figure 11. The transaction begins with the formation of a single purpose reinsurer (SPR). The SPR issues bonds to investors and invests the proceeds in safe securities such as Treasury bonds. Embedded in the bonds is a call option that is triggered by a defined catastrophic event. On the occurrence of the event, proceeds are released from the SPV to help the insurer pay claims arising from the event. In most bonds issued to date, the principal is fully at risk; that is, if the contingent event is sufficiently large, the investors could lose the entire principal in the SPV. In return for the option, the insurer pays a premium to the investors. The fixed returns on the Treasuries are usually swapped for floating returns based on LIBOR or some other widely accepted index. Consequently, the

\footnotetext{
${ }^{14}$ Surplus notes are debt securities issued by mutual insurance companies that regulators treat as equity capital for statutory accounting purposes. The issuance of such notes requires regulatory approval.
} 


\section{Figure 11}

\section{CAT Bond with a Single Purpose Reinsurer}

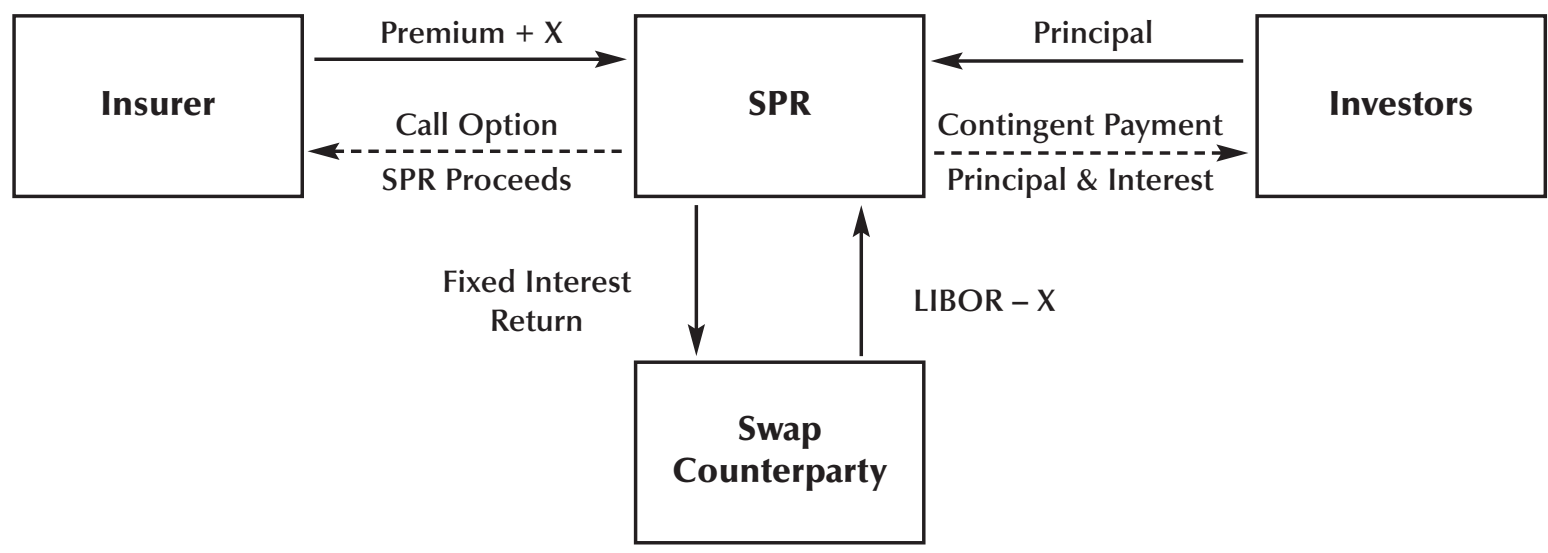

investors receive LIBOR plus the risk premium in return for providing capital to the trust. If no contingent event occurs during the term of the bonds, the principal is returned to the investors upon the expiration of the bonds.

Insurers prefer to use an SPR to capture the tax and accounting benefits associated with traditional reinsurance. ${ }^{15}$ Investors prefer SPRs to isolate the risk of their investment from the general business and insolvency risks of the insurer, thus creating an investment that is a "pure play" in catastrophic risk. As a result, the issuer of the securitization can realize lower financing costs through segregation. The transaction also is more transparent than a debt issue by the insurer, because the funds are held in trust and are released according to carefully defined criteria. The bonds also are attractive to investors because catastrophic events have low correlations with returns from securities markets and hence are valuable for diversification purposes (Litzenberger, Beaglehole, and Reynolds, 1996). Although the \$100-billion-

\footnotetext{
${ }^{15}$ Harrington and Niehaus (2003) argue that an important advantage of CAT bonds as a financing mechanism is that corporate tax costs are lower for CAT bonds than for financing through equity; also, CAT bonds pose less risk in terms of potential future degradations of insurer financial ratings and capital structure than financing through subordinated debt.
}

plus "Big One" hurricane or earthquake could drive down securities prices, creating systematic risk for CAT securities, this systematic risk is considerably lower than for most other types of assets, especially during more normal periods.

In the absence of a traded underlying asset, insurance-linked securities have been structured to pay-off on three types of variables: insuranceindustry catastrophe loss indices, insurer-specific catastrophe losses, and parametric indices based on the physical characteristics of catastrophic events. The choice of a triggering variable involves a trade-off between moral hazard and basis risk. Securities based on insurer-specific (or hedgerspecific) losses, often called indemnity CAT bonds, have no basis risk but expose investors to moral hazard; whereas securities based on industry loss indices or parametric triggers greatly reduce moral hazard but expose hedgers to basis risk.

CAT bonds are an innovative financing solution. ${ }^{16}$ However, although there have been approximately 120 bonds issued to date, the amount of risk capital that has been raised remains small

\footnotetext{
${ }^{16}$ However, the concept is actually not a new one. It is similar to the practice of bottomry, which dates at least to classical Greek and Roman times. In a bottomry contract, the lender extended a loan to finance a voyage. If the ship returned to port, the loan was repaid with interest, but if the ship sank, the loan was forgiven.
} 


\section{Figure 12}

\section{CAT Bonds: New-Issue Volume and Number of Deals, 1998-2005}

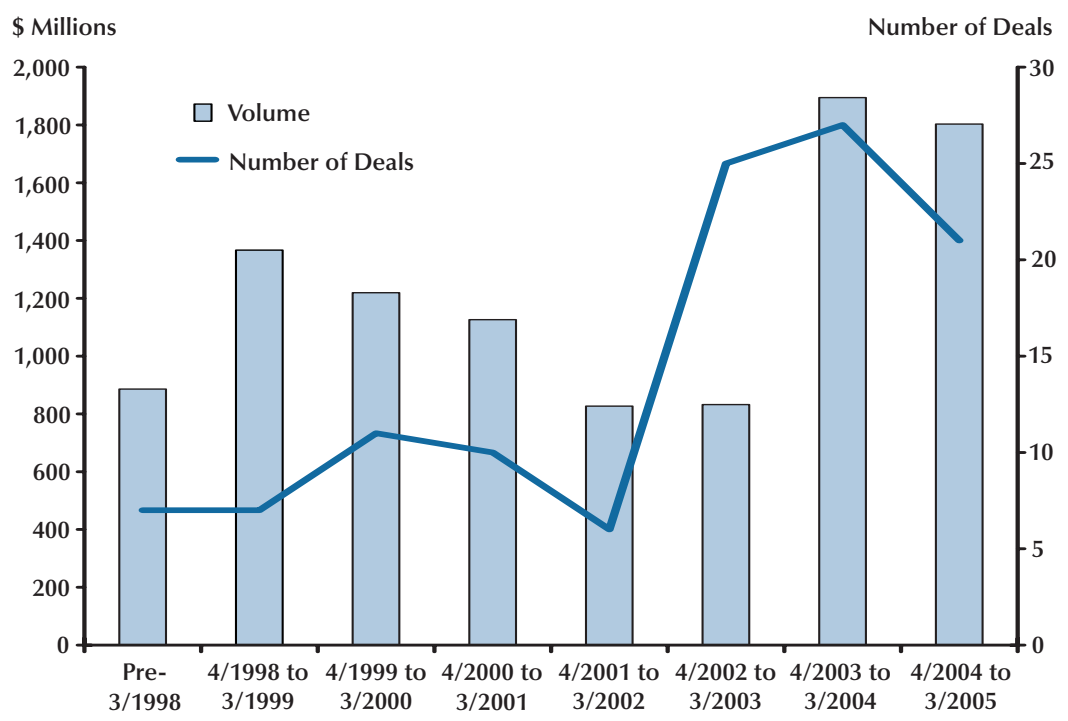

SOURCE: Lane Financial (2005).

relative to the global reinsurance market. The number of issues and risk capital raised are shown in Figure 12, which shows a total of about $\$ 10$ billion raised by March 2005. In comparison, the equity capital of the global reinsurance industry and the U.S. property-casualty insurance industry are approximately $\$ 350$ billion and $\$ 400$ billion, respectively. However, the potential for the use of securities markets to finance catastrophic risk is significant. The amount of asset-backed securities outstanding is nearly $\$ 2$ trillion (Bond Market Association, 2006).

Because of the as-yet unrealized potential of the CAT bond market, it is of interest to explore the possible reasons for the limited amount of risk capital raised to date. One possible explanation is that the bonds appear expensive relative to conventional reinsurance. Structuring a CAT bond deal requires significant expenditures on professional expertise from investment bankers, accountants, actuaries, and lawyers. In addition, the spreads on the bonds have tended to be highoften several times the expected losses on the bonds. ${ }^{17}$
Possible explanations for the high-risk premia on the bonds include investor unfamiliarity with the contracts (a "novelty" premium), the low liquidity of the contracts issued to date (a liquidity premium), and investor uncertainty about the accuracy of the models used to estimate expected losses of the reinsurance (a "model risk" premium). ${ }^{18}$ In addition, although the catastrophic events observed in the United States before the mid-1990s have been uncorrelated with returns in securities markets, this may not be true of a mega-earthquake in California or even a hurricane of the magnitude of Katrina. Thus, the spreads may also reflect a "stealth beta" premium.

\footnotetext{
${ }^{17}$ Cummins, Lalonde, and Phillips (2004) tabulate spreads on CAT bonds issued from 1997 through March of 2000 and find that the median ratio of bond spread to expected loss is 6.77 .

18 The expected losses under CAT bonds are estimated by catastrophe modeling firms such as Applied Insurance Research and Risk Management Solutions. These firms have developed elaborate and highly sophisticated simulation models that simulate catastrophic events using meteorological and seismological models along with actuarial and other modeling approaches. They have constructed extensive data bases on the value of property exposed to loss in the United States and other major countries.
} 


\section{Figure 13}

\section{CAT Bonds Absolute and Relative Yields}

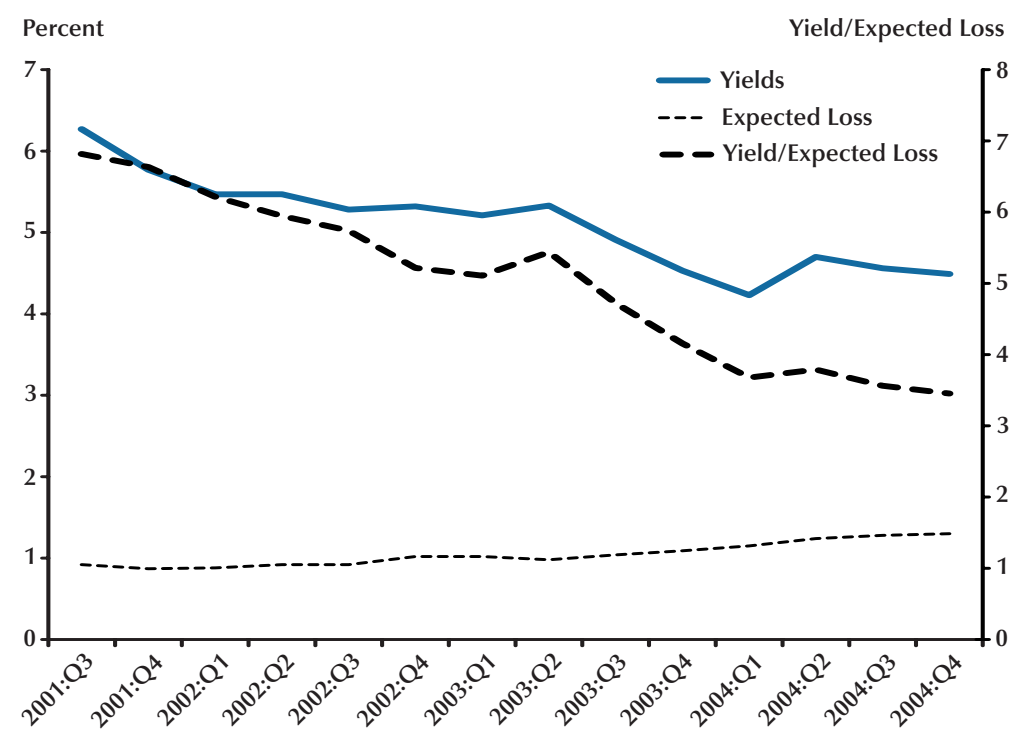

SOURCE: Lane Financial (2005).

Although CAT bonds seem to sell at high premiums over expected losses, in fact, prices of conventional excess-of-loss reinsurance also tend to have high spreads. Froot (2001) documents spreads up to seven times expected losses during the period 1989-98 in the catastrophe reinsurance market. Thus, it is more likely that the high spreads are due to the fact that catastrophe risk is expensive to hedge rather than due to a peculiarity of CAT bonds per se. Moreover, the costs of financing catastrophe risk through CAT bonds have been declining. Investment banks have succeeded in reducing transactions costs as they have gained experience with insurance-linked securitizations, and the spreads on the bonds have fallen over time. This is shown in Figure 13, which plots the average spread on CAT bonds and the average expected loss on the left axis and the ratio of the spread to the expected loss on the right axis, from the third quarter of 2001 through the fourth quarter of 2004. Spreads were averaging 600 basis points at the beginning of the period shown but had declined to about 450 basis points by the end of 2004. In addition, the ratio of the spread to the expected loss declined from around 7 in 2001:Q3 to about 3.5 in 2004:Q4.

Another rationale sometimes given for the limited size of the CAT bond market is lack of investor interest. Although that may have been true at one time, recent data suggest that there is broad market interest in CAT bonds among institutional investors. Figure 14 shows the percentage of new issue volume by investor type in 1999 and 2004. In 1999, insurers and reinsurers were among the leading investors in the bonds, accounting for more than 50 percent of the market; that is, insurers were very prominent on both the supply and demand sides of the market. However, in 2004, insurers and reinsurers accounted for only 7 percent of demand. Money managers and hedge funds bought 56 percent of the 2004 bond issues, and dedicated CAT bond mutual funds accounted for 33 percent. The declining spreads and increasingly broad market interest in the bonds provide some indication that the bonds may begin to play a more important role relative to conventional reinsurance. 


\section{Figure 14}

\section{CAT Bonds: Percentage of New-Issue Volume Purchased by Investor Type}

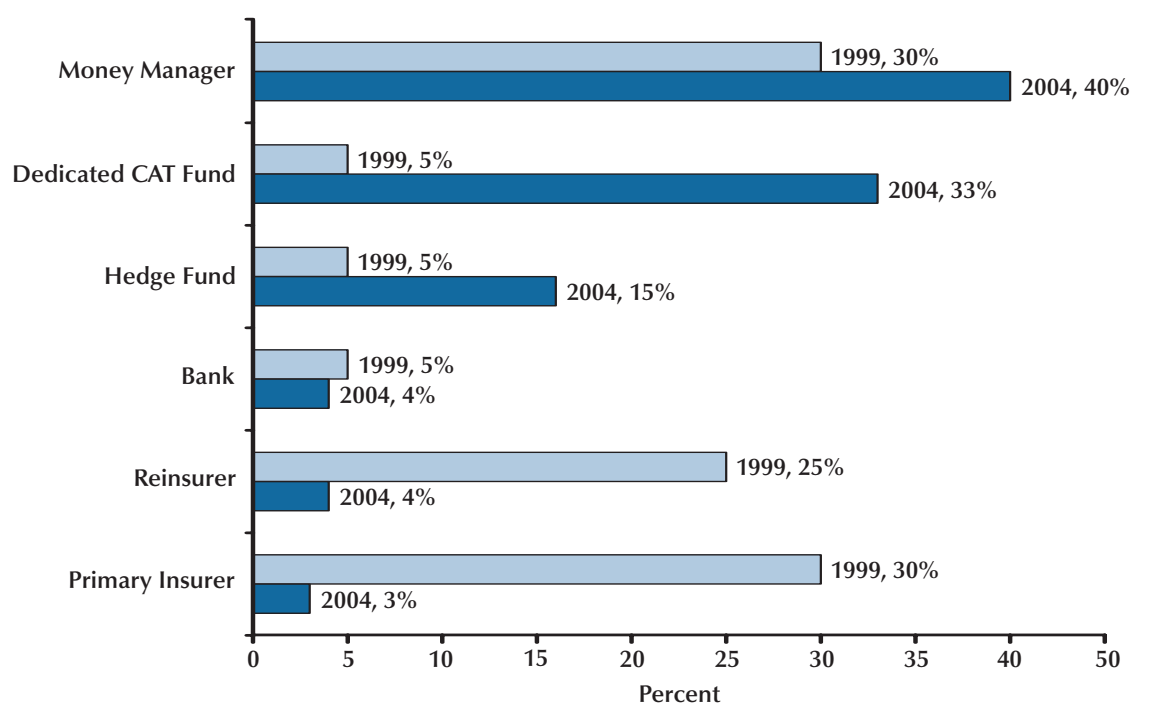

SOURCE: Swiss Re, Economic Research and Consulting.

There are also regulatory and accounting issues that may be impeding the more widespread usage of CAT bonds. U.S. insurance regulators have two concerns about CAT bonds: (i) non-indemnity CAT bonds may expose insurers to excessive basis risk and (ii) insurers may use securitized risk instruments as speculative investments. As a result, some regulators may deny reinsurance accounting treatment for non-indemnity CAT bonds. Fortunately, however, it is relatively straightforward to satisfy both concerns and avoid regulatory problems. Contracts can be structured to pay-off on narrowly defined geographical indices or combinations of indices that are highly correlated with the insurer's losses. Concerns about speculative investing can be addressed through dual-trigger contracts, where two triggers have to be satisfied for the insurer to collect, one based on an industry loss index and the second based on the insurer's own losses from the event. The insurer's payoff is based on its ultimate net loss, a familiar reinsurance concept equal to the insurer's total loss from an event less collections under reinsurance contracts. ${ }^{19}$
A second potential issue mentioned in some discussions is uncertainty about whether SPRs need to be consolidated on insurers' GAAP (generally accepted accounting principles) financial statements under new rules regarding "variable interest entities" (VIEs) that were adopted postEnron. However, based on conversations with industry experts, it appears that properly structured CAT bonds do not encounter problems from VIE rules. With the usual CAT bond structure shown in Figure 11, the SPR is a VIE, but the variability (uncertainty about the payoff from the structure to investors) is entirely passed through to the bond holders. The insurer has no variable (equity ownership) interest but merely pays periodic premiums to the SPR and receives a contingent payout if the defined event occurs. Finally, although CAT bonds have not been granted the tax-free conduit status that is available in the mortgage-backed and asset-backed securities markets, off-shore CAT bonds do not create tax-

\footnotetext{
${ }^{19}$ This dual-trigger approach was developed in the market for industry loss warranties, which is a segment of the reinsurance market offering this type of contract (McDonnell, 2002).
} 
able events for the issuing insurer. The insurer deducts the premium payments to the SPR, and the bond investors pay taxes on the income received from the SPR in the appropriate jurisdiction. Hence, although it would facilitate development of the market to have the regulatory and accounting rules simplified and clarified, these rules currently do not constitute insurmountable obstacles to risk-linked securitizations.

Besides the Chicago Board of Trade options and CAT bonds, other capital market solutions to the problem of financing catastrophic loss have been introduced, including catastrophe equity puts (Cat-E-Puts). Unlike CAT bonds, Cat-E-Puts are not asset-backed securities but options. In return for a premium paid to the writer of the option, the insurer obtains the option to issue preferred stock at a pre-agreed price on the occurrence of a contingent event. This enables the insurer to raise equity capital at a favorable price after a catastrophe, when its stock price is likely to be depressed. Cat-E-Puts tend to have lower transactions costs than CAT bonds because there is no need to set up an SPR. However, because they are not asset-backed, these securities expose the insurer to counterparty performance risk. In addition, issuing the preferred stock can dilute the value of the firm's existing shares. ${ }^{20}$

\section{Government Involvement in Catastrophe Insurance Markets}

The difficulties faced by insurance markets in financing catastrophic risk have given rise to pressures for government to become involved in the market. Government involvement usually occurs when there has been a major failure in private insurance markets. In the United States, the federal government provides subsidized flood insurance; and the current markets for hurricane coverage in Florida and earthquake insurance in California exist largely due to state government intervention. ${ }^{21}$ By adopting TRIA, the U.S. govern-

\footnotetext{
${ }^{20}$ For further discussion of capital market approaches to financing catastrophic risk, see Anderson (2005), Pollner (2001), and Swiss Re (2001). Other innovative solutions, involving hybrids of traditional reinsurance and newer approaches, are discussed in Cummins (2005).

${ }^{21}$ Other states, such as Alabama and Louisiana, have also established
}

ment intervened to create a market for terrorism insurance. Governments of several other industrialized countries have also intervened in the markets for catastrophe insurance. This section provides a review of the principal government programs for catastrophe insurance. Because these programs are subject to book-length treatment elsewhere (e.g., Organisation for Economic Co-operation and Development [OECD], 2005a,b), the discussion of program characteristics is brief. The discussion also emphasizes the programs adopted in the United States.

Federal Flood Insurance. In the United States, the federal government provides flood insurance through the National Flood Insurance Program (NFIP), administered by the Federal Emergency Management Agency (FEMA). The flood program was enacted in 1968 in response to a market failure in the private flood insurance market, where floods were generally viewed as uninsurable because of the concentration of risk in specific areas and the resulting potential for catastrophes (Moss, 1999). Flood insurance was viewed from a policy perspective as a way to prefund disaster relief and provide incentives for risk mitigation. This type of insurance is important because homeowners insurance and other types of property insurance policies exclude coverage for floods.

NFIP flood insurance policies are offered at prices that are subsidized for many buyers and are sold through private insurers, although the federal government bears the risk. The program was designed to be self-supporting and has the ability to borrow from the government to pay claims. The stated objectives of the program are (i) to provide flood insurance coverage to a high proportion of property owners who would benefit from such coverage, (ii) to reduce taxpayer-funded disaster assistance resulting from floods, and (iii) to reduce flood damage through flood-plain management and enforcement of building standards

\footnotetext{
residual market property insurance facilities analogous to the one in Florida; and many other states have Fair Access to Insurance Requirements (FAIR) residual market plans to provide insurance to buyers who cannot find coverage in the voluntary insurance market. I focus here on the California and Florida plans because of their prominence and exposure to large catastrophes.
} 


\section{Cummins}

(Jenkins, 2006). By August 2005, Jenkins (2006) estimated that the NFIP had approximately 4.6 million policyholders in 20,000 communities. From 1968 through August of 2005, the NFIP had paid $\$ 14.6$ billion in insurance claims, primarily funded by policyholder premium payments.

Although the program might seem to be a success (in terms of the amount of coverage provided and claims that have been paid), in fact, the NFIP is badly in need of reform. The program is not actuarially sound, with some policyholders paying premiums representing only 35 to 40 percent of expected costs (Jenkins, 2006). Following the record losses from hurricanes in 2004 and 2005 , the program is currently bankrupt and could not continue to exist in its present state if it were a private insurer. Moreover, the program pays significant amounts of money to repair or replace "repetitive-loss properties;" that is, properties that receive loss payments of $\$ 1,000$ or more at least twice over a 10-year period. It is estimated that such properties, which represent only 1 percent of covered properties, account for 25 to 30 percent of all loss payments (Jenkins, 2006). Insurance penetration rates are low, even in the most flood-prone areas, with as little as 50 percent of exposed properties covered by insurance. In Orleans Parish, which includes New Orleans, only about 40 percent of properties were covered by flood insurance at the time Katrina struck (Bayot, 2005) and coverage rates were even lower in parts of Mississippi. The NFIP also has been criticized for not providing effective oversight of the approximately 100 insurance companies and thousands of insurance agents and claims adjusters who participate in the flood program (Jenkins, 2006).

Reforming the NFIP should become a top priority for federal disaster planning. Having high rates of flood insurance coverage can significantly reduce taxpayer-funded disaster-relief payments following catastrophes, and charging actuarially sound premiums would provide proper incentives for flood-plain management. ${ }^{22}$ There are two approaches that could be taken to reforming the program: (i) Continue providing federal flood

${ }^{22}$ For further discussion of the role of insurance in risk mitigation, see Kunreuther (1996). insurance but fix the problems with the current program. This would entail charging premiums sufficient to cover both claims and program expenses and providing a safety cushion to build up reserves during low-loss years to reduce the need for federal borrowing during years when catastrophes occur. Further, other problems identified by the GAO would also need to be rectified. (ii) Adopt a solution with a higher degree of private sector involvement. This could be done following the pattern of the federal terrorism program by requiring private insurers to "make available" private flood insurance policies at actuarially determined prices in flood-prone areas. Although it is probable that private insurers could provide such coverage without federal support, by issuing disaster bonds (similar to CAT bonds) and through conventional reinsurance solutions, consideration should be given to providing federal reinsurance at prices that would be self-supporting in the long run. The private sector solution is attractive for a number of reasons, including the relative efficiency of insurers in settling insurance claims in comparison with the often chaotic federal response to disaster relief. Under either solution to NFIP reform, rules should be tightened to eliminate repetitive-loss properties from the program, and lenders should be required to enforce mandatory participation in the program as a condition for granting and retaining mortgage loans, as is presently done for homeowners insurance.

\section{Windstorm Coverage in California and}

Florida. Windstorm coverage is presently provided by private insurers through homeowners and other property insurance policies. The California and Florida programs are noteworthy in that they do not involve the direct government provision of insurance but the creation of quasigovernmental entities not supported by taxpayers.

Following the 1994 Northridge earthquake, the market for earthquake insurance in California collapsed as private insurers stopped writing coverage. The California legislature responded in 1996 by creating a quasi-public entity, the California Earthquake Authority (CEA), to provide earthquake insurance to Californians. The CEA is not a government agency but operates under 
constraints mandated by the legislature. Specifically, the policies written by the CEA are earthquake "mini-policies" designed by the legislature that provide less-extensive coverage than provided by private insurers pre-Northridge. The legislature also mandated that coverage be provided at sound actuarial prices, although these have been "tempered" somewhat to subsidize policyholders in high-risk areas. The legislature also required that the CEA be funded by capital contributions of about $\$ 700$ million from private insurers licensed in California in lieu of requiring them to write earthquake insurance. The CEA had claims-paying ability of about $\$ 6.9$ billion at the end of 2004 (PricewaterhouseCoopers, 2005). Putting this in perspective, recall that the Northridge earthquake caused insured losses of $\$ 18.5$ billion (Table 1 ). However, because of the mini-policies and because fewer residences have earthquake insurance now than before 1994, it is probable that the CEA could withstand damages on the scale of Northridge.

Since the creation of the CEA, private insurers have re-entered the California earthquake market. In 2004, approximately 150 companies wrote nonzero earthquake insurance premiums in California (California Department of Insurance, 2005). Of the $\$ 985$ million in California earthquake premiums written in 2004, however, the CEA accounted for 47.3 percent; and private insurers generally write insurance in relatively low-risk areas of the state (Jaffee, 2005). Nevertheless, the design of the CEA, and especially its mandate to charge actuarially justified premium rates, has had the effect of not crowding-out the private sector. Something of a puzzle in the California market, however, is that only a small proportion of eligible property owners actually purchase the insurance. In the homeowners market, 33 percent of eligible properties purchased earthquake insurance in 1996, the CEA's first year, but only 13.6 percent had insurance in 2003. The rationale usually given for the low market penetration is that most buyers consider the price of insurance too high for the coverage provided, even though premiums are close to the expected losses (Jaffee, 2005).

As in California following Northridge, the hurricane market in Florida was significantly destabilized by Hurricane Andrew in $1992 .{ }^{23}$ In response to insurer attempts to withdraw and reprice windstorm coverage following the event, the state placed restrictions on the ability of insurers to decline renewal of policies and to increase rates. To provide an escape valve for policyholders who were unable to obtain coverage, the state created the Florida Residential Property and Casualty Joint Underwriting Association (FRPCJUA), a residual market facility. Insurers doing business in the state were required to be members of the facility, which insured people and businesses who could not obtain property coverage from the voluntary insurance market. The FRPCJUA was empowered to assess insurers if premiums were not sufficient to pay claims, and there was no explicit government backing. A similar residual market facility was formed to provide "wind only" coverage along the coastthe Florida Windstorm Underwriting Association.

In 2002, the two residual market plans were merged to form the Citizens Property Insurance Corporation, a tax-exempt entity that provides coverage to Floridian consumers and businesses who cannot find coverage in the voluntary market. Citizens operates like an insurance company in charging premiums, issuing policies, and paying claims. If premiums are insufficient, it has the authority to assess insurers doing business in the state to cover the shortfall. It also has the ability to issue tax-exempt bonds if necessary. Citizens was severely stressed by the four hurricanes that hit Florida in 2004, as it struggled to handle the massive numbers of claims that were filed. In 2004 , Citizens wrote $\$ 1.4$ billion in premiums, accounting for 34 percent of the Florida property insurance market. Unlike California earthquake insurance, the market penetration of property insurance coverage in Florida is very high, in part because mortgage lenders require mortgagors to purchase insurance.

To provide additional claims-paying capacity, Florida also created the Florida Hurricane Catastrophe Fund (FHCF), a state-run catastrophe reinsurance fund designed to assist insurers writ-

${ }^{23}$ For further economic analysis of the Florida windstorm insurance market, see Grace, Klein, and Liu (2006). 


\section{Cummins}

ing property insurance in Florida. Insurers writing residential and commercial property insurance in the state are required to purchase reinsurance from the FHCF based on their exposure to hurricane losses in the state. The FHCF does not have state financial backing. However, it is operated as a state agency and is exempt from federal income taxes, enabling it to accumulate funds more rapidly than private insurers. In addition, the fund has the authority to assess member insurers within limits in case premiums and reserve funds are insufficient and also has the ability to issue taxexempt bonds. The catastrophe reinsurance issued by the fund kicks in after an industry retention of $\$ 4.5$ billion, and the fund has claims-paying ability of about $\$ 15$ billion. The FHCF helped to stabilize the property insurance market following the 2004 hurricane season and Hurricane Wilma in 2005.

The California and Florida experience shows that government can play an important role in making insurance available without directly committing taxpayer funding. These programs also have the virtue of not crowding-out private insurers, although it is possible that the mandatory purchase feature of the FHCF may have crowdedout some private reinsurance. However, because these are government-mandated and -designed programs, they probably are not as efficient as purely private market solutions.

Terrorism Insurance. Prior to the September 11, 2001, terrorist attacks, terrorism was generally covered by most property-casualty insurance policies. In fact, the risk was considered so minimal by insurers that terrorism was usually included at no explicit price. Likewise, reinsurers generally covered primary companies for terrorism as part of their reinsurance coverage; and reinsurers paid most of the claims resulting from the WTC attack. After 9/11, however, reinsurers began writing terrorism exclusions into their policies, leaving primary insurers with virtually no opportunity to reinsure their exposure. As a result, the primary insurers sought to write terrorism exclusions into their own policies.

Recognizing that substantial exposure to terrorism risk without adequate reinsurance could pose insolvency risks, state insurance regulators rapidly approved terrorism exclusions. By early 2002, insurance regulators in 45 states allowed insurers to exclude terrorism coverage from most of their commercial insurance policies. ${ }^{24}$

In February 2002, the Government Accounting Office (GAO) gave congressional testimony providing "examples of large projects canceling or experiencing delays...with the lack of terrorism coverage being cited as the principal contributing factor" (Hillman, 2002, p. 9). According to a survey by the Council of Insurance Agents and Brokers, in the first quarter of 2002, the market for propertycasualty insurance experienced "sharply higher premiums, higher deductibles, lower limits and restricted capacity from coast to coast and across the major lines of commercial insurance." ${ }^{25}$ In November 2002, Congress responded to these problems by passing TRIA. Through TRIA, the federal government required property-casualty insurers to offer or "make available" terrorism insurance to commercial insurance customers and created a federal reinsurance backstop for terrorism claims.

TRIA established the Terrorism Insurance Program within the Department of the Treasury. The program, which has been extended through December 31, 2007, covers commercial propertycasualty insurance-all insurers operating in the United States are required to participate. Insurers are required to "make available property and casualty insurance coverage for insured losses that does not differ materially from the terms, amounts, and other coverage limitations applicable to losses arising from events other than terrorism" (U.S. Congress, 2002, p. 7). The legislation thus nullified state terrorism exclusions and requires that insurers offer terrorism coverage. The wording of the Act implicitly omits coverage of chemical, biological, radiological, and nuclear (CBRN) haz-

\footnotetext{
${ }^{24}$ An exception to the general exclusion of terrorism from commercial insurance policies following $9 / 11$ is coverage for workerscompensation insurance, which is mandated by state law to cover work injuries from all causes. The states did not revise the workerscompensation laws to allow terrorism exclusions. Terrorism exclusion also were not introduced for personal-lines policies such as automobile and homeowners insurance.

${ }^{25}$ Council of Insurance Agents and Brokers (2002).
} 


\section{Figure 15}

\section{Coverage Under the TRIA of 2002}

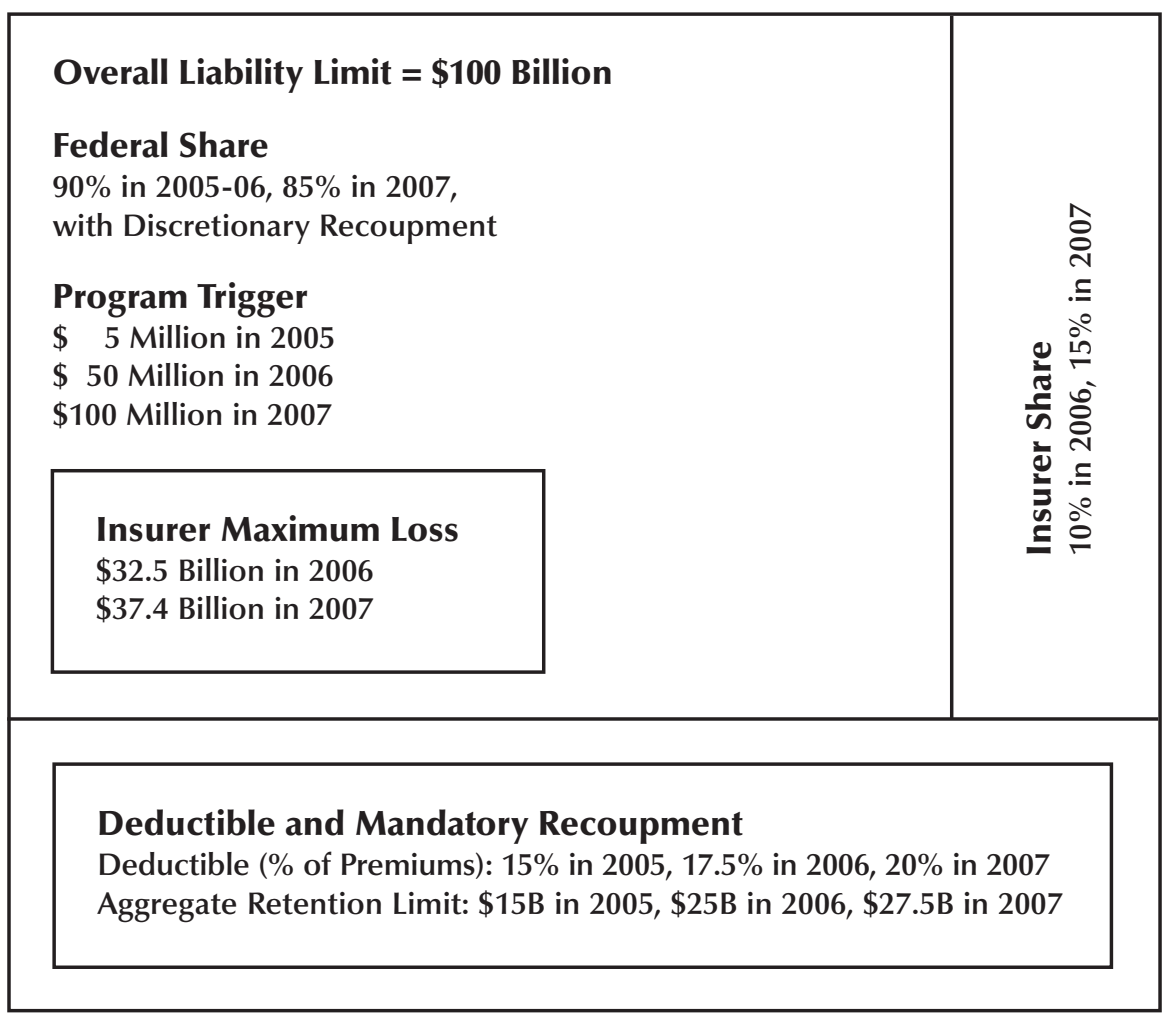

NOTE: TRIA as extended by the Terrorism Risk Insurance Extension Act of 2005.

SOURCE: GAO (2004), Marsh (2005b).

ards, which are not covered by most commercial property-casualty policies. ${ }^{26}$

For the federal government to provide payment under TRIA, the Secretary of the Treasury must certify that a loss was due to an act of terrorism, defined as a violent act or an act that is dangerous to human life, property, or infrastructure, and to have "been committed by an individual or individuals acting on behalf of any foreign person or foreign interest, as part of an effort to coerce the civilian population of the United States

\footnotetext{
${ }^{26}$ The TRIA Extension Act in 2005 excluded some types of commercial insurance that had been covered under the original TRIA. Specifically, coverage was eliminated for commercial auto, burglary, surety, professional liability, and farmowners multiple-peril insur-
} ance (Marsh, 2005b). or to influence the policy... of the United States Government by coercion" (U.S. Congress, 2002, p. 3). Acts of war are excluded, and losses from any terrorist act must exceed a specified monetary threshold before the Act takes effect. The threshold was originally $\$ 5$ million, increasing to $\$ 50$ million in 2006 and $\$ 100$ million in 2007.

If a loss meets these requirements, the loss is shared by the insurance industry and the federal government under the deductible, copayment, and recoupment provisions of the Act. The coverage structure of the Act is diagramed in Figure 15. In 2005, each individual insurer had a terrorism insurance deductible of 15 percent of its direct earned premiums from the prior calendar year, which increases to 17.5 percent in 2006 and 20 
percent in 2007. Above the deductible, the federal government pays for 90 percent of all insured losses in 2005-06, decreasing to 85 percent in 2007. However, the law provides for mandatory recoupment of the federal share of losses up to the level of the "insurance marketplace aggregate retention," which is $\$ 15$ billion in 2005, \$25 billion in 2006, and $\$ 27.5$ billion in 2007. This recoupment is to occur through premium surcharges on property-casualty insurance policies in force after the event, with a maximum surcharge of 3 percent of premiums per year. In addition, the Secretary of the Treasury has the discretion to demand additional recoupment, taking into account the cost to taxpayers, the economic conditions of the commercial marketplace, and other factors. In other words, the Secretary of the Treasury could choose to recoup 100 percent of federal outlays under this program through ex post premium surcharges. The total, combined liability of the government and private insurers is capped at $\$ 100$ billion.

In both 2006 and 2007, insurers are exposed to potentially large losses under TRIA. As shown in Figure 15, the deductible and recoupment provisions expose insurers to possible losses as high as $\$ 32.5$ billion in 2006 and $\$ 37.4$ billion in 2007 . Although these losses would be large by historical standards, they are of the same order of magnitude as the losses from the World Trade Center and Katrina, which the industry was able to absorb. In addition, the analysis of Cummins, Doherty, and Lo (2002) suggests that the industry could sustain losses of this magnitude without destabilizing insurance markets.

Government Catastrophe Insurance in Other Countries. This section provides a brief overview of the government role in catastrophe insurance in other countries based on OECD (2005a,b), GAO (2005), and other sources. Natural disaster programs are discussed first, followed by terrorism.

In many OECD countries, governments use tax revenues to establish prefunded disaster-relief funds. This approach is used in countries such as Australia, Denmark, Mexico, the Netherlands, Norway, and Poland (Freeman and Scott, 2005). In several of these countries, the government provides compensation only for losses that cannot be privately insured. This approach is somewhat similar to the disaster-relief funding provided by the federal government in the United States.

Several countries have established government insurance programs to provide coverage for natural disasters. The government collects premiums in return for the coverage, and private insurers generally market the policies and handle claims settlement and other administrative details. An example is Consorcio de Compensacion de Seguros (CCS), which was established by the Spanish government in 1954. CCS is a public corporation that provides insurance for "extraordinary risks," including both natural catastrophes and terrorism. The extraordinary risks coverage is mandatory and is provided as an add-on to private market property insurance policies. A premium is collected for the coverage, which is passed along to CCS by the private insurers.

Another approach, somewhat similar to TRIA, is for the government to act as a reinsurer rather than a primary insurer as it does in Spain. An example is France, which has two programs, the National Disaster Compensation Scheme and Fonds National de Garantie des Calamites Agricoles. The former is backed by a stateguaranteed public reinsurance program, Caisse Centrale de Reassurance (CCR), which provides unlimited government backing for catastrophe losses. Catastrophe insurance is mandatory for all private non-life insurance policies. Insurers can then reinsure the risk with CCR, which essentially serves as reinsurer of last resort. Premium surcharges for the catastrophe insurance are set by the French government.

Another example of the government as reinsurer is provided by the Japan Earthquake Reinsurance Company, which reinsures natural hazards such as earthquakes and tsunamis in Japan. All earthquake insurance written by private insurers in Japan is reinsured with the Japan Earthquake Reinsurance Company. Reinsurance coverage is based on a layering approach, such that 100 percent of the loss in the lowest-loss layer, up to 75 billion yen, is borne by private insurers; the loss is split evenly between private insurers and the government when the loss is between 75 billion and 1.0774 trillion yen; and 95 percent of 
the loss is paid by the government when the loss is between 1.0774 and 4.5 billion yen (Freeman and Scott, 2005).

According to the OECD (2005b), there are government terrorism insurance programs in eight OECD countries: Australia, Austria, France, Germany, the Netherlands, Spain, the United Kingdom, and the United States. All of the programs were established after the September 11, 2001, terrorist attacks except for the Spanish program, where coverage is provided by CCS, and the U.K. program, which was established in 1993 in response to Irish Republican Army terrorist attacks. The programs vary along several important dimensions, including coverage layers and amounts, the limitations on the liability of private insurers, whether a premium is charged for the government reinsurance, and whether the plan is temporary or permanent. In the following, I give examples based on the most prominent plans rather than providing a comprehensive analysis.

In December 2001, a new reinsurer called Gestion de l'Assurance et de la Reassurance des Risques Attentats et Actes de Terrorisme (GAREAT) was established in France to reinsure terrorism risk insurance written by private insurers. The French government acts as reinsurer of last resort, providing unlimited reinsurance coverage through CCR. As is common in conventional catastrophe reinsurance, government terrorism reinsurance coverage is provided in a sequence of layers. The first layer of 400 million euros of coverage is provided by the private insurers who participate in GAREAT. As of 2005, there are two layers of private market reinsurance: The first layer provides limits of 1.2 billion euros in excess of the 400 million euro primary layer, and the second layer provides 400 million euros in excess of 1.6 billion euros. Above 2 billion euros, unlimited coverage backed by a government guarantee is provided by CCR. As with other catastrophe insurance in France, terrorism coverage is mandatory for all property insurance. A premium is collected for the government reinsurance, which is remitted to the government. GAREAT is set to expire at the end of 2006 (Michel-Kerjan and Pedell, 2005).

In Spain, terrorism insurance is provided under the CCS program. Therefore, it is mandatory for all non-life insurance. There is no layering. All extraordinary risks coverage is ceded to CCS, which is backed by an unlimited government guarantee. Policyholders pay a premium surcharge for the coverage provided by CCS, including terrorism coverage. The program is permanent.

In Germany, a specialist insurer, EXTREMUS, was established in 2002 to provide terrorism insurance. The program is set to terminate at the end of 2007. Coverage is not mandatory in Germany, and demand for terrorism insurance is reportedly very low. The first 2 billion euros of coverage is provided by private insurers and reinsurers, and there is excess reinsurance coverage ( 8 billion euros in excess of 2 billion euros) provided by the German government in return for a premium. The annual maximum indemnity for each client is limited to 1.5 billion euros.

In the United Kingdom, a mutual reinsurance company, Pool Re, was established in 1993 to provide terrorism reinsurance to insurers writing insurance in the United Kingdom. Pool Re has a retrocession arrangement with the British Treasury to provide the ultimate layer of reinsurance. The first layer of coverage is provided by primary insurers, up to 75 million pounds per event or 150 million pounds per year (in 2005), industrywide. Coverage is then provided by Pool Re up to the full amount of its resources. Coverage for events that exhaust the funds in Pool Re is provided by the government in return for a premium.

Among the eight OECD terrorism programs covered in OECD (2005b), only Austria's does not involve some form of government insurance. Among the seven programs with government backing, five are temporary and four have fixed expiration dates. Government reinsurance is unlimited in France, Spain, and the United Kingdom. Among the countries with limits on the liability of the government reinsurance, the highest limit is in the U.S. TRIA program. Among the programs with government backing, only the U.S. program does not charge a premium for the reinsurance, although the Secretary of the Treasury has the authority to seek recoupment of losses exceeding the industry participation limits. The lack of a premium is a defect in the U.S. program because it has the effect of crowding-out private reinsurers, who cannot compete with free coverage. 


\section{Figure 16}

\section{Stock Price Impact of the Passage of TRIA (11/20/2002)}

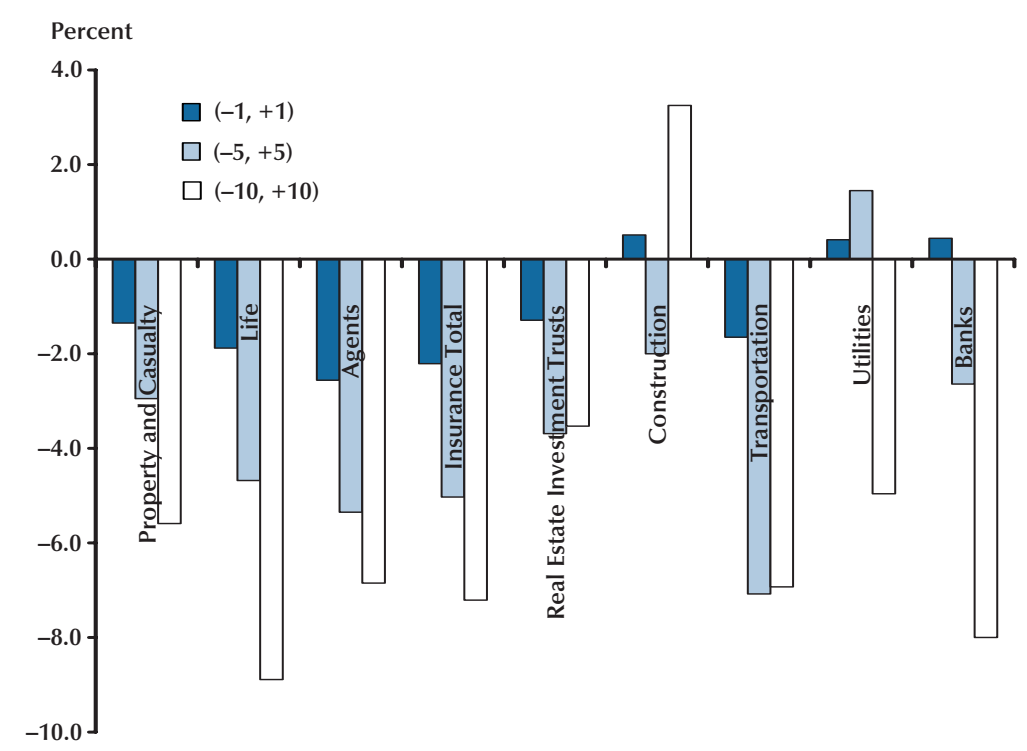

SOURCE: Brown et al. (2004).

An Evaluation of TRIA. In making the case for TRIA, the president of the United States, Congress, and business leaders argued that the lack of terrorism insurance was having an adverse effect on important segments of the economy, citing cancelled or postponed construction projects, downgrades of commercial and multi-family mortgage securities, and other deleterious effects. However, the evidence was mostly anecdotal and solid evidence of a macroeconomic impact from the restrictions on terrorism insurance during 2002 has been hard to find. One paper that looked at several macroeconomic time series, such as bank construction lending and new construction put in place, did not find any noticeable interruption in trends that had existed before September 11, 2001 (Brown et al., 2004). ${ }^{27}$ Nevertheless, the general assumption has been that restrictions on terrorism insurance are bad

27 A paper by Hubbard and Deal (2004) purports to show that the expiration of TRIA would have a significant adverse impact on the macroeconomy. However, the paper appears to have been written as an advocacy document, and the analysis is not very convincing. for the economy, providing a rationale for a federal role. This section briefly considers the macroeconomic impact of TRIA, analyzes TRIA's success in restoring the market for terrorism insurance, and evaluates the likely impact if TRIA eventually expires.

Brown et al. (2004) provide evidence on the expected economic effects of TRIA by investigating the stock price reaction to the Act's adoption on the industries most likely to be affected by terrorism insurance. They conduct a standard event study of 11 TRIA-related news announcements, culminating in the president signing the bill into law on November 26, 2002. The stock price impact on affected industries of the bill's passage by Congress on November 20, 2002, is representative of the general conclusions of the study. The results, shown in Figure 16, reveal that TRIA's passage had an adverse impact on the stock prices of firms in the insurance, banking, real estate investment trusts, and transportation industries and a negative long-window impact on public utilities. Only in the construction industry is there any evidence of a positive stock price impact from TRIA, and 
this effect is not statistically significant. The results imply that TRIA's passage caused the stock market to reduce its estimates of expected future cash flows in nearly all affected industries.

It is relatively easy to explain the negative stock price reaction of property-casualty insurers to the passage of TRIA. Prior to TRIA, the availability of terrorism insurance was sharply curtailed, revealing that many insurers did not believe they could write terrorism insurance at a profit. TRIA nullified most coverage restrictions and required insurers to offer coverage that they did not want to provide and, moreover, exposed insurers to significant potential losses from TRIA's deductible, copayment, and recoupment provisions. Although TRIA left the pricing of terrorism insurance to the private market, states regulate insurance prices; and attempts by insurers to avoid providing coverage by offering insurance at excessive prices would attract adverse regulatory attention. Thus, as shown further below, a considerable amount of terrorism insurance has been offered under TRIA that probably would not have been available without TRIA's "make available" rule.

Because the purchase of terrorism insurance is not mandatory under TRIA, it is more difficult to explain the adverse stock price reaction in industries that are buyers rather than sellers of insurance. At first glance, the Act provided firms in these industries with a no-obligation option to buy terrorism insurance that may not have been available otherwise. However, a more careful look reveals some possible reasons for the negative stock price reaction. Brown et al. (2004) provide two possible explanations. A first explanation is a type of "Samaritan's dilemma" problem. That is, the Act may have reduced market expectations with respect to future federal assistance for firms and industries affected by terrorist events by substituting a federal reinsurance program for a potentially more open-ended implicit government commitment. The second explanation is that TRIA may have created insurance market inefficiencies by impeding the development of more-efficient private market mechanisms for financing terrorism losses, especially because no premium is charged for the federal reinsurance. A third possible explanation, which conflicts somewhat with the Samaritan's dilemma argument, is that TRIA implicitly excludes coverage for CBRN hazards, which have the potential to cause the most severe losses.

Although initial reports indicated that take-up rates (the percentage of buyers who accept insurers' offers of terrorism insurance) under TRIA were very low, more recent data reveal that significant amounts of terrorism insurance have been purchased under TRIA. Marsh $(2004,2005 a)$ surveyed their clients in 2004 and 2005 to provide information on terrorism coverage. The results are shown in Figure 17, which provides quarterly take-up rates based on approximately 2,400 Marsh clients from 2003:Q2 to 2004:Q4. The take-up rate increased from 23 percent in 2003:Q2 to 48 percent in 2004:Q4. Thus, the large firms which constitute Marsh's clientele demonstrated a significant demand for terrorism insurance, especially in 2004.

Further evidence on terrorism insurance take-up rates is provided by surveys conducted by the U.S. Department of the Treasury (2005) as part of its congressional mandate to provide an evaluation of TRIA's effectiveness. The Treasury surveys are a valuable complement to the Marsh surveys because they also included smaller firms. The results, shown in Figure 18, indicate that the take-up rate increased from 27 percent in 2002 to 54 percent in 2004 . This provides further evidence that a strong demand for terrorism insurance has existed under TRIA. The 2002 results are also important because they reveal that terrorism insurance did not disappear between September 11, 2001, and the passage of TRIA. In fact, significant amounts of coverage were being offered and purchased during this period, even though no federal reinsurance was in effect.

The final source of evidence on take-up rates is a survey conducted in 2004 by the Mortgage Bankers Association (2004). The Association surveyed the commercial and multi-family mortgage market to determine the prevalence of terrorism insurance protection for properties covered by these types of mortgages. The results, shown in Figure 19, reveal that lenders require terrorism insurance for mortgages, accounting for about 94 


\section{Cummins}

\section{Figure 17}

\section{Terrorism Insurance Take-Up Rates: Marsh Estimates}

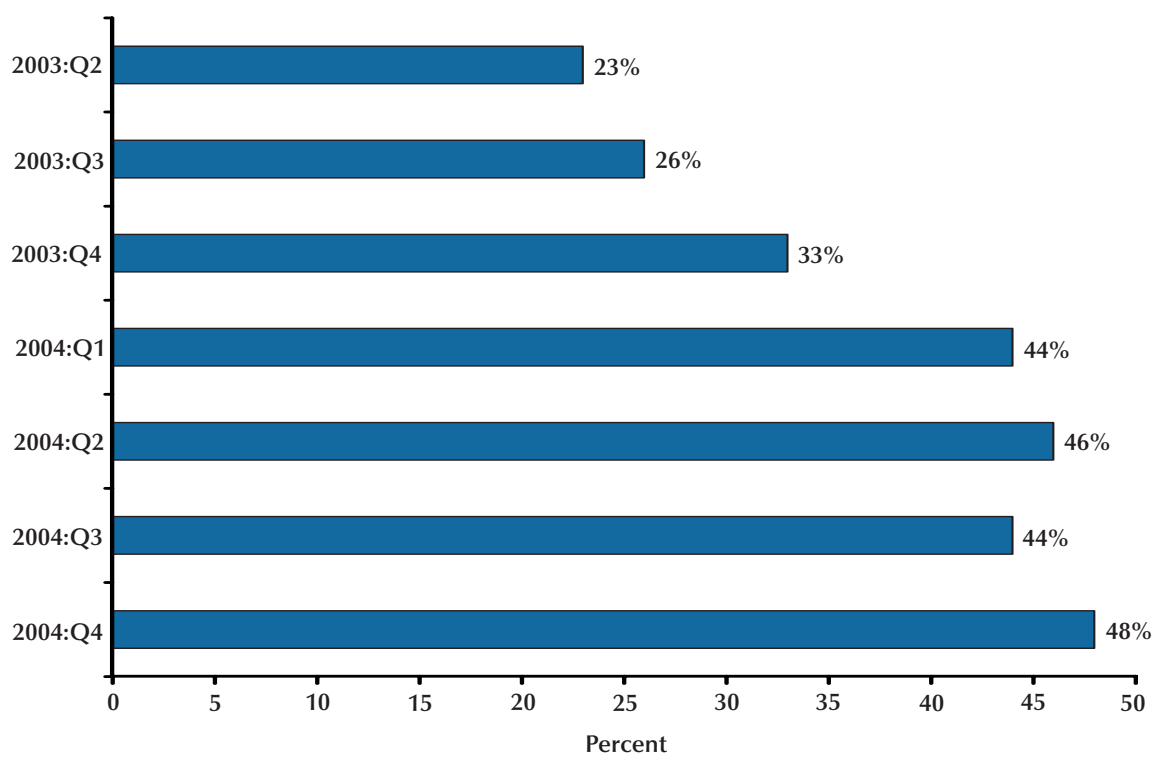

SOURCE: Marsh (2005a).

\section{Figure 18}

\section{Policyholder Terrorism Insurance Take-Up Rates}

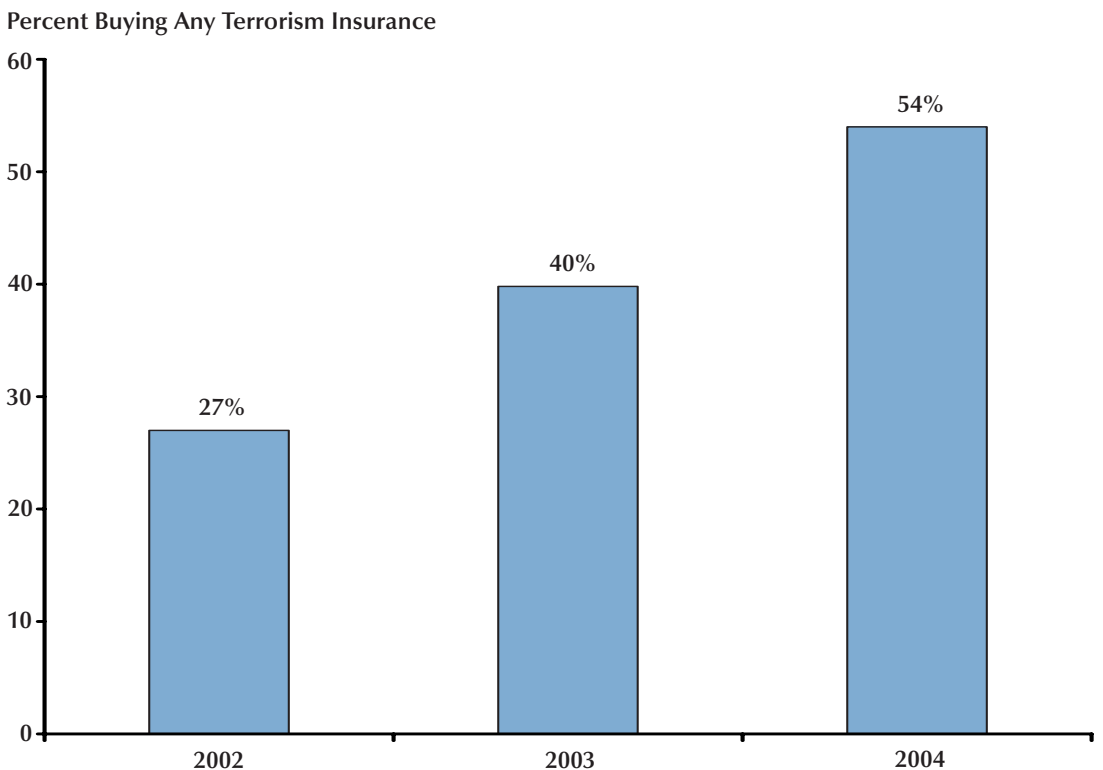


Figure 19

Terrorism Insurance in the Commercial/Multi-family Mortgage Market, 2004

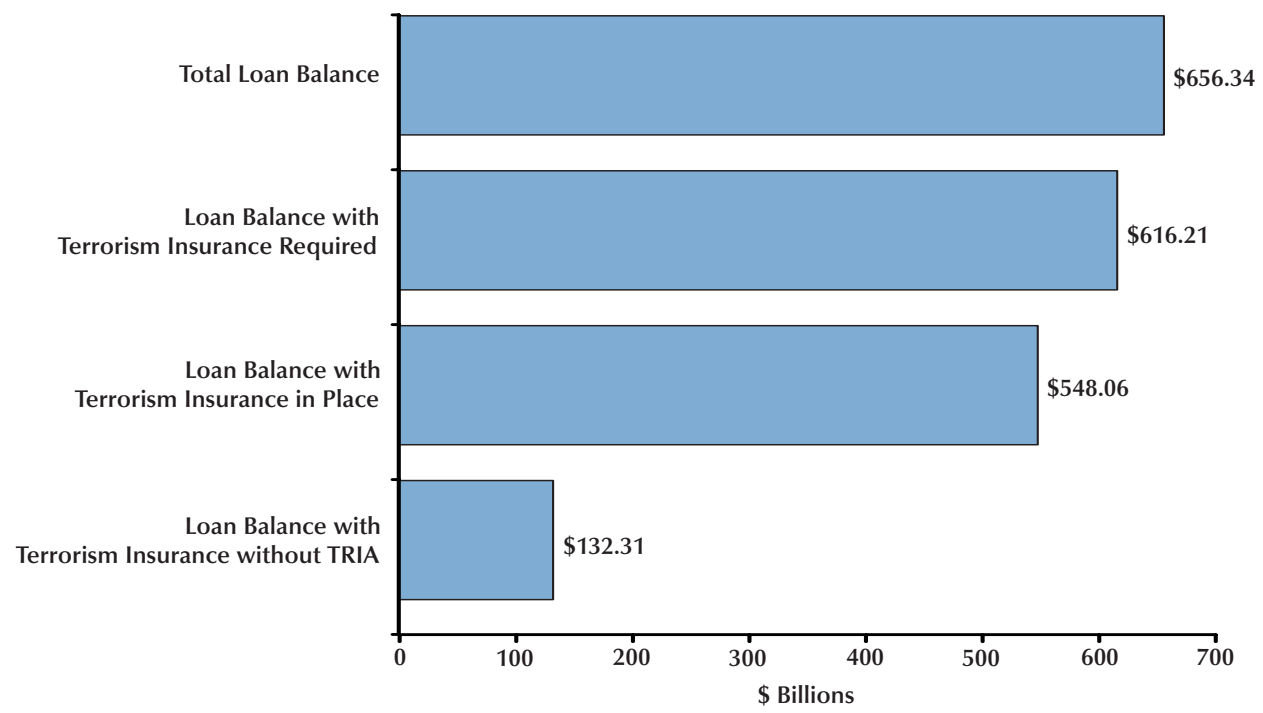

SOURCE: Mortgage Bankers Association (2004).

Figure 20

Terrorism Insurance Price as a Percentage of Property Insurance Premiums

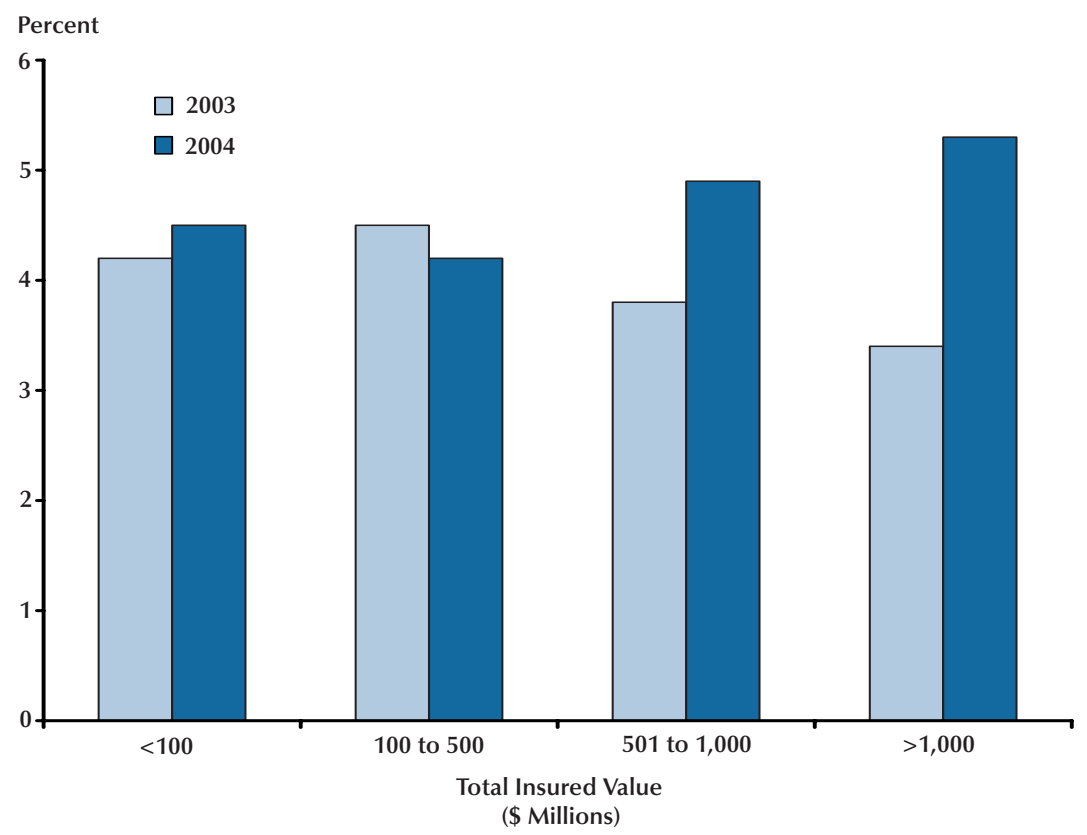


Figure 21

\section{Terrorism Insurance Pricing: Median Rates by Total Insured Value}

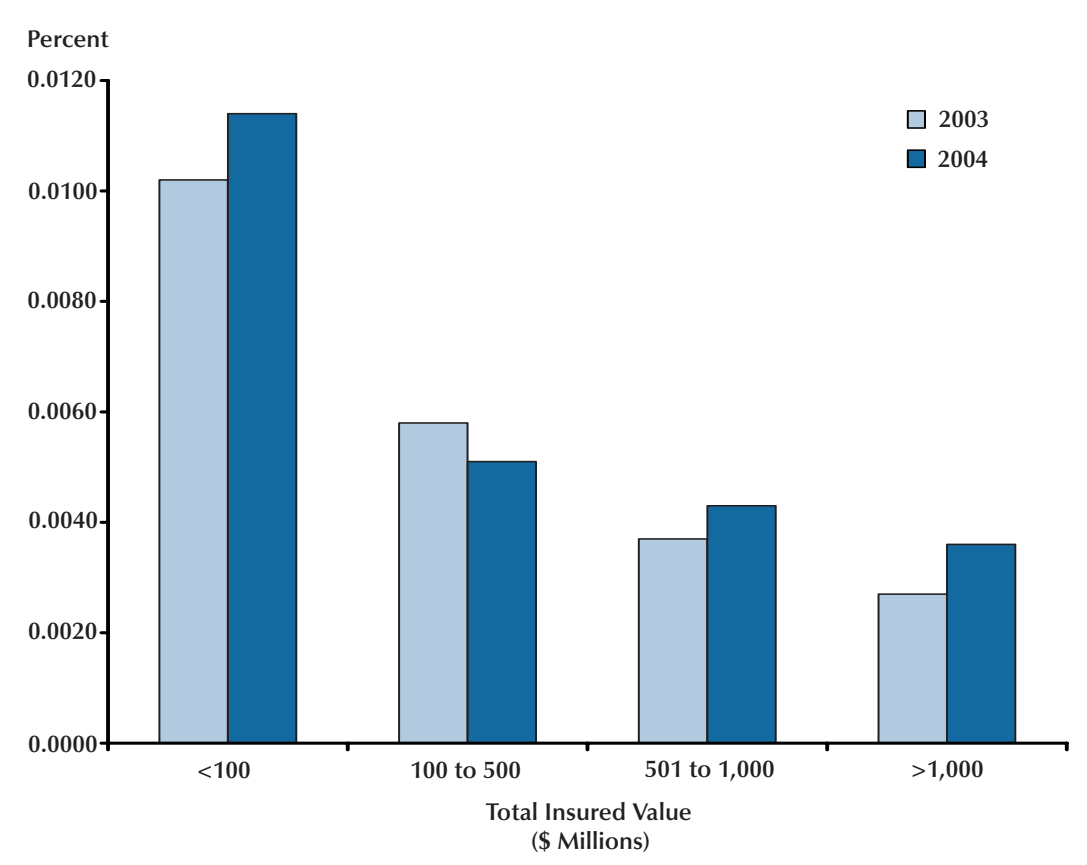

SOURCE: Marsh (2005a).

percent of loan balances. Of the $\$ 616$ billion in loan balances where terrorism coverage was required, insurance was purchased for $\$ 548$ billion, or 89 percent. Respondents estimate that only $\$ 132$ billion would have been covered by terrorism insurance absent TRIA. Although the accuracy of this counterfactual estimate is not clear, the results do indicate the respondents' belief that TRIA plays a major role in creating a supply of terrorism insurance.

The pricing of terrorism insurance was also analyzed in the Marsh and U.S. Treasury surveys. Results from Marsh (2005a) are presented in Figure 20. The figure indicates that terrorism insurance constituted between 4 and 5 percent of total commercial property insurance premiums for the Marsh clients included in the survey and that prices increased in 2004 for larger properties. However, even at the 2004 levels, prices do not seem unreasonable in a relative sense. Figure 21 provides information on the absolute values of terrorism insurance prices from the Marsh survey.
Terrorism insurance premiums represented 0.01 percent of insured value for relatively low-valued properties, dropping to about 0.004 percent for the largest properties.

Further pricing results from the Treasury surveys are summarized in Figure 22. Perhaps surprisingly, the results reveal that many insurers were still not charging an explicit price for terrorism insurance following the enactment of TRIA. In 2002, about 80 percent were not charging for terrorism coverage, but this had dropped to 40 percent by 2004. Including both the zero price and positively priced insurance, terrorism insurance accounted for about 1 percent of total property insurance premiums in 2002, rising to approximately 2 percent in 2004. Considering only the positive-premium terrorism insurance, the terrorism premium was about 3 percent of total premiums in 2004. Hence, the price of terrorism coverage does not seem to be exorbitant under TRIA.

I now turn to an evaluation of what the terrorism insurance market might look like without 
Figure 22

\section{Terrorism Insurance Premiums as a Percentage of Total Premiums}

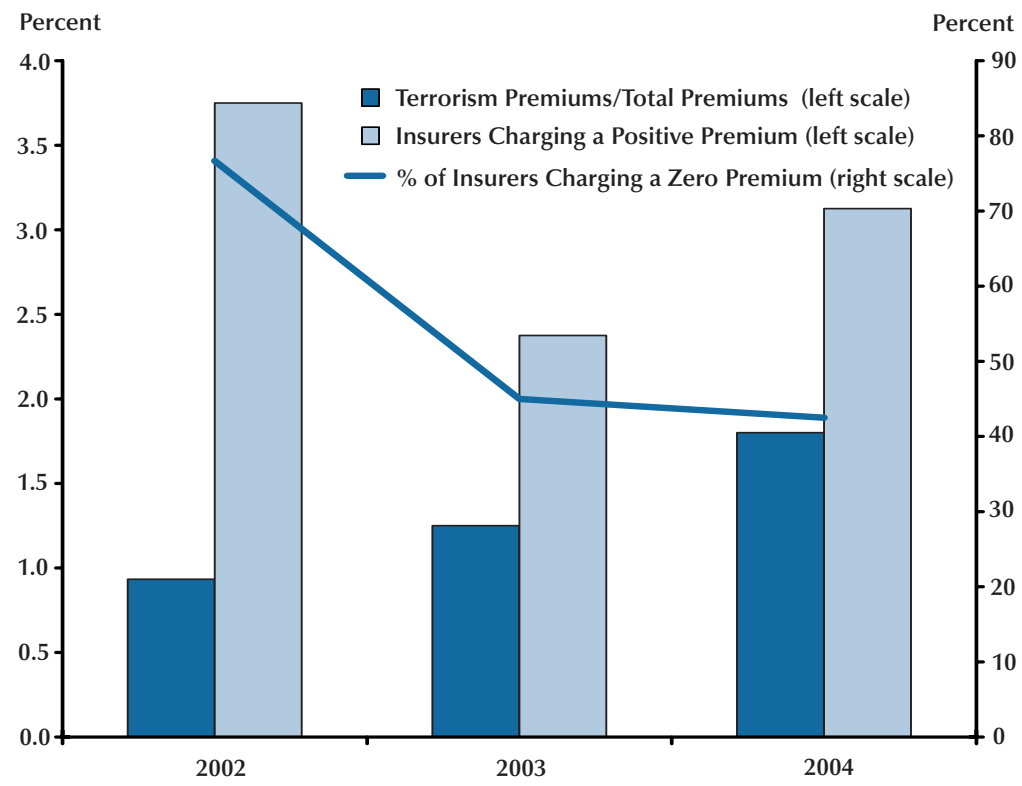

SOURCE: U.S. Department of the Treasury (2005).

Figure 23

\section{Extent of Terrorism Coverage}

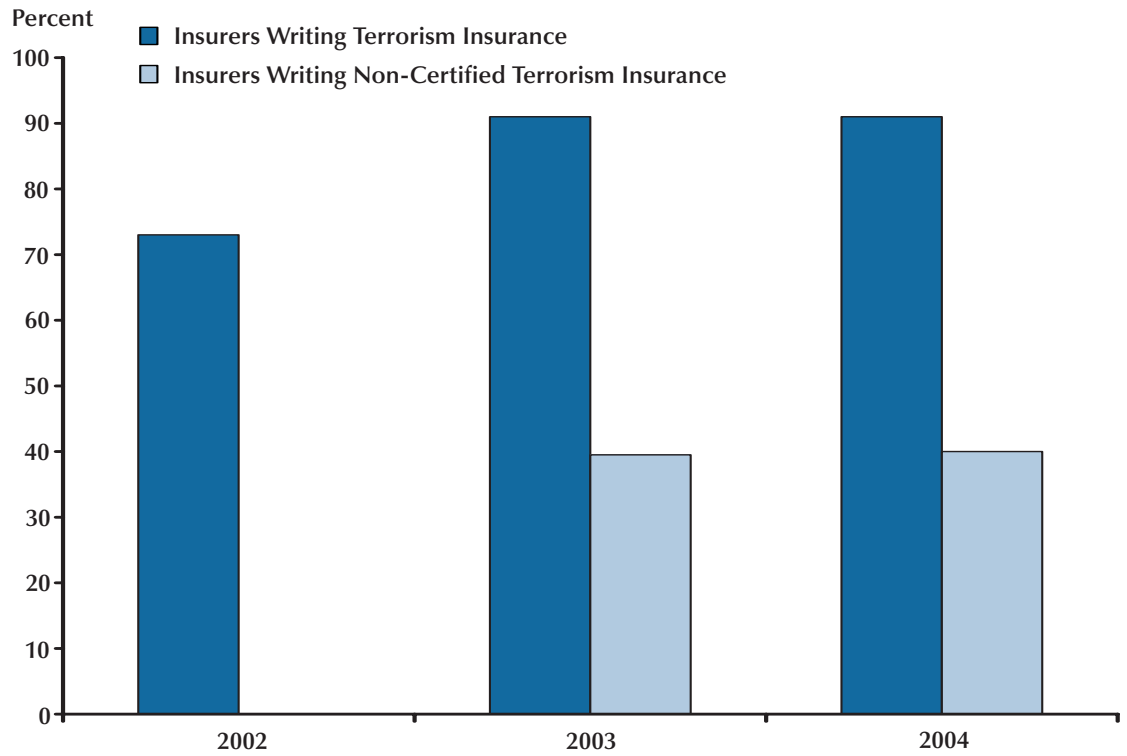

SOURCE: U.S. Department of the Treasury (2005). 


\section{Cummins}

TRIA. Some evidence helpful in making this evaluation is provided in the U.S. Treasury surveys. In addition to terrorism insurance reinsured under TRIA, which is limited to foreign terrorism, some insurers also write non-certified terrorism coverage, which insures against events such as domestic terrorism not covered by TRIA. The percentages of insurers writing certified (i.e., TRIA-reinsured) coverage and non-certified coverage for 2002 through 2004 are shown in Figure 23. ${ }^{28}$ The results are striking-approximately 90 percent of insurers wrote certified terrorism coverage in 2002 through 2004, but only 40 percent wrote non-certified coverage. Given that non-certified (i.e., domestic) terrorism events are generally viewed as less risky than foreign terrorism, these results may suggest that no more than 40 percent of insurers would continue to offer terrorism coverage for foreign terrorism if TRIA expires.

The Treasury also queried responding insurers about their 2005 renewals that extend into 2006, when TRIA's renewal was uncertain. Fifty percent of the respondents indicated that they would not provide terrorism coverage "that is roughly similar to TRIA coverage" for the segment of the policy period extending into 2006 (U.S. Treasury 2005, p. 75). Of these respondents, 55 percent planned to exclude terrorism altogether in 2006, 22 percent had a contingent exclusion for terrorism going into 2006, and 24 percent included coverage that was not comparable to TRIA coverage. These results do not bode well for the availability of terrorism insurance coverage absent TRIA.

In conclusion, it is clear that TRIA has been effective in making terrorism insurance widely available. That about half of policyholders do not buy terrorism insurance seems to be more a reflection of the fact that many policyholders do not have significant terrorism exposure rather than a belief that terrorism prices are too high. In fact, terrorism coverage is being made available at prices representing only a small proportion of total property insurance premiums. However, because the government reinsurance is being provided for free, it is likely that the current prices mainly reflect insurer expected losses under the

${ }^{28}$ This distinction is not meaningful in 2002 because federal terrorism reinsurance did not exist for most of the year. deductible and copayment provisions of TRIA. Thus, prices can be expected to rise once the terrorism deductibles, copayments, and recoupment provisions increase beginning in 2006.

The survey results also suggest that availability of terrorism insurance is likely to decline sharply if TRIA eventually expires. This could be a temporary decline until private market solutions begin to emerge. However, the experience with catastrophic risk insurance in California and Florida suggests that many buyers, especially in high-risk areas, will not be able to obtain terrorism insurance without some form of government involvement in the market. Although such involvement does not necessarily imply that the government should serve as reinsurer of last resort, the experience of other OECD countries suggests that some form of government reinsurance may be needed to sustain the market for terrorism coverage in the future. However, care should be taken in designing any federal terrorism program, to avoid adverse incentives and unintended consequences. For example, an economic analysis conduced by Michel-Kerjan and Kunreuther (2006) shows that it would be possible for large insurers to "game" the system under TRIA, shifting responsibility for terrorism losses to smaller insurers and policyholders. ${ }^{29}$

\section{EVALUATION OF GOVERNMENT INVOLVEMENT MECHANISMS}

This section begins with an evaluation of theories of government involvement in insurance markets. The discussion then turns to an evaluation of the principal mechanisms for government involvement and recommendations for improving the markets for insurance against catastrophes.

\section{Theories of Government Involvement}

Three primary theories of public policy are relevant in evaluating the role of government in addressing market failures in the insurance indus-

\footnotetext{
${ }^{29}$ For further economic analysis of terrorism insurance, see Kunreuther and Michel-Kerjan (2004), Kunreuther et al. (2003), Lakdawalla and Zanjani (2002), and Wharton Risk and Decision Processes Center (2005).
} 
try: laissez faire, public interest, and market enhancement. Laissez faire theory maintains that any market-based equilibrium, however imperfect, provides a more efficient allocation of resources within the economy than an equilibrium involving government intervention. From this perspective, government intervention in markets results primarily from rent-seeking behavior of special interest groups (e.g., Stigler, 1971). Thus, industry calls for government protection against catastrophic risk are viewed as opportunistic attempts to secure an ex ante wealth transfer from taxpayers.

Several types of inefficiencies can arise from government insurance programs. Provision of subsidized insurance is likely to crowd out private attempts to enter the market, permanently lockingin an inefficient solution to financing catastrophe losses. Government programs tend to develop constituencies that engage in intensive lobbying to maintain government support, strengthening concerns about rent-seeking by special interests. ${ }^{30}$ Subsidized insurance also tends to create moralhazard problems whereby policyholders underinvest in loss prevention. Government insurance also may create resource allocation problems if subsidized terrorism insurance leads to overbuilding of building types and locations that are relatively vulnerable to terrorism. Actuarial pricing of government insurance can alleviate some of these problems. However, because the design of government programs is determined by politics rather than the operation of markets, even unsubsidized insurance programs are not likely to represent the most efficient solution.

The public interest theory of regulation contests the laissez faire view (e.g., Musgrave and Musgrave, 1984). This theory suggests that market failures can lead to suboptimal allocation of resources and that government intervention targeted at addressing the market failures can improve welfare. Although laissez faire policy suggests that private sector coordination is optimal, public interest theory suggests that, in specific instances, the government can improve upon

\footnotetext{
${ }^{30}$ At least one lobbying group, the Council to Insure Against Terrorism, was formed specifically to lobby for renewal of TRIA on behalf of business insurance buyers. Several groups representing insurance agents and insurance companies also have active TRIA lobbying efforts.
}

the market equilibrium by substituting for private sector coordination. Proponents of public interest theory, therefore, maintain that the information asymmetries and bankruptcy costs associated with the market for terrorism insurance may necessitate the role of the government in "completing" the market for terrorism insurance.

The third view of public policy intervention, the market-enhancing view, takes a middle position (e.g., Lewis and Murdock, 1999). The marketenhancing view recognizes that market failures can create suboptimal allocations of wealth and that private sector coordination is not always effective. This view holds that public policy should facilitate the development of the private market but should not create new governmental institutions to substitute for private solutions. The marketenhancing policy recognizes that government (de)regulation can help facilitate the creation or enhancement of private institutions for solving market failures, such as how the federal government facilitated mortgage securitization markets. ${ }^{31}$

\section{Mechanisms for Government Involvement}

This section first considers natural catastrophes and then analyzes terrorism. The private insurance market seems to have difficulty in providing adequate coverage for the largest natural catastrophes. Projected catastrophes, such as a $\$ 100$ billion California earthquake or Florida hurricane, are large relative to the resources of the insurance industry; and holding additional equity capital in the industry to shield against such events does not seem to be feasible (Jaffee and Russell, 1997). GAAP accounting rules do not allow insurers to establish reserves for events that have not happened. Similarly, insurers are not permitted to take tax deductions for events that have not yet occurred, requiring that capital to pay for catastrophe claims has to be accumulated out of after-tax income. ${ }^{32}$ In addition, large pools

\footnotetext{
${ }^{31}$ Of course, there is always the risk that government-sponsored enterprises' special privileges may remain fully in place years later, even if the market failures no longer exist.

${ }^{32}$ It is noteworthy that both the California Earthquake Authority and Florida's residual market and catastrophe insurance plans have been allowed to establish reserves using pre-tax revenues.
} 


\section{Cummins}

of capital tend to attract corporate raiders and may induce management to engage in negative net-present-value projects. Raising capital to pay losses following a large-loss event also is difficult because informational asymmetries between capital markets and insurers regarding loss exposure and reserve adequacy raise the cost of capital to potentially prohibitive levels. Thus, private insurance markets tend to be much more efficient at cross-sectional rather than cross-time diversification.

There are several possible solutions to the cross-time diversification problem. Because the resources of capital markets are more than adequate to fund large catastrophes, a market-enhancing approach would be for the government to facilitate the growth of the insurance-linked securities market. This is an attractive solution because it could be implemented without committing tax dollars to paying for catastrophe losses. There are several areas where removal of remaining regulatory and bureaucratic barriers as well as simplification and clarification of rules and approval procedures would facilitate the securitization of catastrophic risk. The GAAP consolidation rules should be clarified and codified for CAT-linked securities, and such securities should be given conduit status for federal income tax purposes. State insurance regulations should be clarified and streamlined to reduce transactions costs and enhance the speed to market of new securities.

Even if all regulatory impediments were removed, the CAT bond market still might not attain sufficient size to fund major catastrophes. However, it is also possible that "critical mass" would be reached, where scale economies and the ability to form worldwide CAT bond portfolios would reduce transactions costs and spreads to the point where the market would rival the assetbacked securities market. The costs of relaxing the regulatory and accounting rules are low, so it would seem to be worthwhile to conduct the experiment. The federal government could play a major role by creating a task force to coordinate with Congress, the Financial Accounting Standards Board, and the National Association of Insurance Commissioners to bring down the regulatory barriers.
A somewhat more intrusive solution to the time diversification problem would be to exploit the federal government's ability to implement intergenerational diversification through federal borrowing. Unlike private insurers, the federal government can effectively accomplish cross-time diversification because it can raise money following a disaster by borrowing at the risk-free rate of interest. ${ }^{33}$ The government's ability to timediversify led to a Clinton administration proposal for government intervention in the market for catastrophe property insurance (Lewis and Murdock, 1999), whereby the federal government would hold periodic auctions of catastrophe excess-of-loss (XOL) reinsurance contracts to insurers and reinsurers in loss layers where private market reinsurance is not available. The auctions would be conducted subject to a reservation price sufficient to support the expected loss and expense costs under the contracts as well as a risk premium to encourage private market "crowding out" of the federal reinsurance. If a catastrophe were to occur that triggered payment under the contracts, the federal government would finance the loss payments by issuing bonds. Although the proposal was not adopted, it could provide a model for a different type of federal involvement in the terrorism insurance market consistent with the marketenhancing view of regulation. However, given that securitization offers a viable private market solution, it would be advisable to give higher priority to exploring that option.

Another alternative to government intervention to enhance the private market would be to permit insurers to accumulate tax-deductible reserves for catastrophe losses, a proposal that has been advocated by the insurance industry for at least a decade. One obvious problem with the proposal is that it would reduce federal tax revenues, when other solutions such as securitization are available that would not have this effect. Another problem is that there would be no way to prevent insurers from reducing reinsurance purchases in such a way as to substitute taxadvantaged reserves for other forms of hedging,

\footnotetext{
${ }^{33}$ The assertion that the government has superior ability to timediversify may be challenged on the grounds that it places risks on taxpayers regardless of their willingness to bear them.
} 
with little or no net gain in risk-bearing capacity. Finally, a tax-subsidized reserving program would have a crowding-out effect on the securitization market.

As mentioned above, state governments have intervened to "make markets" in catastrophe insurance in California, Florida, and other states. These might be considered market-enhancing efforts, except to the degree that they involve an element of coercion. That is, insurers are required to participate in the California and Florida programs if they wish to continue to participate in the states' other lucrative insurance markets, such as the market for automobile insurance. It is likely that less insurance would be available in these states, at least on a cyclical basis, if the statemandated plans had not been adopted. However, it is also possible that the private market would provide adequate coverage if insurance prices were deregulated, allowing the market to clear. The periodic difficulties in private markets for natural catastrophe coverage provide additional impetus for developing the CAT bond market because insurers might be more willing to write coverage on a voluntary basis if more reasonably priced diversification mechanisms were available for mega-catastrophes.

The market response to the increasing frequency and severity of catastrophe insurance losses since the 1990s has potentially quite significant implications. In spite of the lack of federal government intervention in the market for natural catastrophe insurance, the private market for natural catastrophe insurance did not collapse completely. Although insurance and reinsurance prices rose following Andrew and Northridge, significant amounts of new equity capital flowed into the industry and reinsurance prices eventually declined (Guy Carpenter, 2005). For the most part, insurance continued to be available in disaster-prone areas, such as Florida, and private insurers eventually re-entered the market for California earthquake insurance. There is evidence of continuing market anomalies, however, such as the skewness of reinsurance toward the coverage of relatively small catastrophes and the thinness of reinsurance coverage for mega-catastrophes (Froot, 2001). Nevertheless, private markets for natural catastrophe insurance have continued to function with reasonable efficiency in the absence of federal support.

Terrorism, and particularly mega-terrorism events, pose more-difficult problems for private insurance markets than natural catastrophesmega-terrorism events potentially cause much more extensive losses than natural hazards; the frequency and severity of terrorist events are difficult to estimate, both inherently and because much of the most useful information is confidential for national security reasons; and terrorists can adjust strategies and tactics to defeat efforts to protect against terrorism and mitigate loss severity. The same factors that make terrorism difficult to insure and its similarity to war risk may rule out terrorism-risk securitization, at least on a large scale. Among the other obstacles, the existence of terror-linked securities might influence target selection by terrorists, and terrorists and their sympathizers could attempt to profit by trading in terror-linked securities. ${ }^{34}$ Consequently, even if government provision of insurance against natural catastrophes is not needed, there may be a legitimate role for government in the market for terrorism insurance. The experience under TRIA provides somewhat mixed messages on the need for a government role-the stock market reacted negatively to the adoption of TRIA but survey evidence strongly suggests that TRIA succeeded in making terrorism coverage widely available.

There are various mechanisms for government to become involved in the terrorism insurance market. Because there is great uncertainty surrounding the insurability of terrorism risk, a guiding principle of any government involvement should be that programs be designed to not crowd out the private market. This necessitates that the program be explicitly priced and that the price

\footnotetext{
${ }^{34}$ However, there is some evidence that securities markets might provide a source of risk-bearing capacity for terrorist events. In 2003, the Golden Globe Financing transaction resulted in a \$260 million securitization covering the risk of the cancellation of the 2006 FIFA World Cup. The transaction explicitly included terrorism risk. Swiss Re has executed two securitization transactions covering catastrophic mortality risk, including mortality spikes from terrorism. A key to the success of these issues may be that they are multi-event bonds, not applying strictly to terrorism (Swiss Re, 2005b).
} 


\section{Cummins}

be set above the expected value of loss. One possibility would be to adapt the Clinton administration proposal and auction off federally backed XOL terrorism reinsurance contracts. Another would be a reinsurance program patterned after TRIA but with a positive premium charge and continuing increases in insurance industry deductibles to encourage the private market to develop gradually.

Another important problem is how to handle CBRN hazards. Under TRIA, the federal policy approach is to "look the other way" and to permit insurers to exclude CBRN hazards to the extent they were excluded from non-terrorist commercial coverages. In this respect, CBRN hazards are being treated similarly to war risks. If an XOL reinsurance or TRIA-like program is to be implemented going forward, a case could be made for including CBRN hazards. Because government is likely to compensate CBRN victims after the fact, it might make sense to handle as much compensation as possible through a formal insurance program rather than as disaster relief. As Katrina has shown, the federal response to a disaster can be chaotic and inefficient, whereas private insurers are very effective at settling claims and have incentives to settle them efficiently provided the government insurance has appropriate deductibles and copayment provisions to control moral hazard.

\section{CONCLUSIONS}

The frequency and severity of losses from natural catastrophes such as hurricanes, earthquakes, and tsunamis have increased dramatically in the past 15 years. Even though the resources of insurers and reinsurers worldwide also have grown, the rising costs of catastrophic risks have placed significant stress on insurance markets. Man-made disasters also have led to monetary losses and loss of life. However, until the terrorist attacks of September 11, 2001, terrorism losses did not fall into the mega-catastrophe category; and, in fact, insurers routinely covered terrorism losses for little or no charge. The 9/11 losses revealed a shift in the terrorism probability of loss distribution, which led insurers and reinsurers to exclude terrorism losses from many insurance policies. Governments in several countries responded by adopting government terrorism insurance programs. The U.S. Terrorism Risk Insurance Act of 2002 (TRIA) requires insurers to offer terrorism coverage in commercial propertycasualty insurance policies and provides federal terrorism reinsurance. This paper investigates the appropriateness of government insurance programs for catastrophic risk, focusing on coverage for natural catastrophes and terrorist events.

A review of the resources of the insurance and reinsurance industries as well as the current state of the market for insurance against earthquakes and windstorms in the United States reveals little need for a government role, beyond the programs currently in effect in Florida and California. Adequate insurance is now available in the states with the highest exposure to natural catastrophes. The earthquake and hurricane insurance markets in the United States fall under the category of a second-best solution; that is, better than an alternative system involving a moreintrusive role for government

Although few policyholders in California purchase earthquake coverage, windstorm insurance is widely purchased in Florida. The lack of interest in earthquake coverage among buyers in California is a matter of concern, and the resources of the California Earthquake Authority (CEA) would be inadequate to pay claims from a major earthquake if coverage were more widespread. This situation is likely to lead to pressures for massive governmental disaster relief following a major earthquake. Hence, measures should be considered, such as making earthquake insurance mandatory in quake-prone areas of the state and strengthening the resources of the CEA, on the hypothesis that it is more efficient to provide assistance through prearranged programs where claims are settled by private industry rather than by ex post government assistance programs.

Even though government insurance for hurricanes and earthquakes does not seem to be needed, government could deepen and enhance the markets for these and other catastrophe coverages by removing regulatory impediments to the development of the market for insurance-linked 
securities. This would involve clarifying and/or changing GAAP accounting rules for specialpurpose reinsurers, granting insurance-linked securities conduit status for federal tax purposes, and giving non-indemnity securities reinsurance status under state regulatory accounting rules. Giving insurers the ability to accumulate catastrophe reserves on a pre-federal income tax basis would reduce federal tax revenues without necessarily adding net capacity to insurance markets.

The federal government is already involved in the market for flood insurance, providing subsidized insurance through the National Flood Insurance Program. However, the program is badly in need of reform. It is currently bankrupt and generally does not charge actuarially sound premiums or have a provision for building up reserves in low-loss years to minimize the need for federal borrowing to pay claims. Flood insurance penetration rates are very low, and the program is not effectively meeting its stated objectives of encouraging loss mitigation and flood-plain management. Although the program could and should be fixed, a better alternative would be to develop private sector solutions by requiring insurers to make available flood insurance coverage, perhaps with a federal reinsurance backstop, and requiring lenders to enforce flood-coverage requirements, as is presently done for homeowners insurance.

Terrorism is a more difficult problem for private insurance markets than natural hazards, for several reasons. Terrorism is a deliberate act, similar to war, which has long been excluded from private insurance policies. Moreover, because terrorists can potentially use weapons of mass destruction, terrorism losses are potentially much larger than losses from natural hazards. Terrorism losses are also much more difficult to estimate than losses from natural catastrophes. Prediction is made especially difficult because terrorists are constantly changing strategies, targets, and tactics. Finally, the likelihood of terrorist attacks is affected by government policies for homeland security, foreign affairs, and defense; and much of the information that would be useful to insurers in estimating premiums remains confidential for national security reasons. Consequently, a case can be made for some degree of government involvement in the terrorism insurance market.

Terrorism insurance did not disappear after 9/11, and some coverage will undoubtedly continue to be available if TRIA eventually expires. However, a review of survey data provides convincing evidence that terrorism insurance is much more widespread under TRIA than it would have been with no government reinsurance in place. Thus, insurance availability will decline, at least initially, if government reinsurance is withdrawn, especially for the most vulnerable targets and locations. As with natural catastrophes, it is likely to be more efficient to cover terrorism losses through a pre-existing insurance program rather than through ex post government assistance. Fairly priced terrorism insurance also provides the proper incentives for resource allocation in terms of the siting of construction projects and private mitigation efforts.

If government does continue to participate in the terrorism insurance market, care should be taken that the program does not prevent the re-emergence of the private market. In particular, terrorism insurance should be priced at the expected loss plus a sufficient risk margin to make it attractive for private reinsurers to re-enter the market and to encourage the development of a terrorism risk-linked securities market. Any government terrorism reinsurance should have industry deductibles at least as large as under TRIA. Consideration also should be given to covering the chemical, biological, radiological and nuclear hazards under public and private terrorism insurance. Finally, care should be taken in designing any government terrorism program, to avoid creating adverse incentives and prevent gaming of the system by insurers or other market participants.

Future research is needed to determine the effects of catastrophe losses and catastrophe insurance on the macroeconomy. Although catastrophe losses are small relative to U.S. and world GDP, it is still unclear whether such losses and/or the availability of insurance coverage have significant macroeconomic effects. It would be useful to further analyze the relationship between catastrophes and macroeconomic time series, such as construction, bank loans, and mortgages, as well as the 


\section{Cummins}

correlations of catastrophes with securities returns. Such information would be valuable both to policymakers and to participants in the catastrophe insurance and insurance-linked securities markets. Finally, the experience with Hurricane Katrina suggests that the time has come for a comprehensive re-evaluation of disaster assessment, prevention, mitigation, and financing in the United States.

\section{REFERENCES}

A.M. Best Company. Best's Aggregates and Averages. Oldwick, NJ: Various years.

Anderson, Torben J. "International Financing Solutions to Terrorism Risk Exposures," in Terrorism Risk Insurance in OECD Countries. Paris: OECD Publishing, 2005.

Bayot, Jennifer. "Hurricane Katrina: Insurance; Payouts Hinge on the Cause of Damage." New York Times, August 31, 2005, Late Edition, Section C, p. 5.

Berger, Lawrence; Cummins, J. David and Tennyson, Sharon. "Reinsurance and the Liability Insurance Crisis.” Journal of Risk and Uncertainty, July 1992, 5(3), pp. 253-72.

Bond Market Association. “Asset Backed Securities Outstanding By Major Types of Credit: 19952005:Q4.” New York: 2006; www.bondmarkets.com/story.asp?id=84.

Brown, Jeffrey R.; Cummins, J. David; Lewis, Christopher M. and Wei, Ran. "An Empirical Analysis of the Economic Impact of Federal Terrorism Reinsurance." Journal of Monetary Economics, July 2004, 51(5), pp. 861-98.

California Department of Insurance. "Earthquake Coverage Experience: Summary of Residential Market Share 2003 Experience Year.” Los Angeles: 2004.

California Department of Insurance. "2004 California Property and Casualty Market Share Report.” Line of Business: Earthquake. Los Angeles: 2005, pp. 40-43.
Council of Insurance Agents and Brokers. "Council Releases 1st Quarter 2002 Market Index.” Press release, April 16, 2002.

Council of Insurance Agents and Brokers. Commercial Property-Casualty Market Survey: Second Quarter 2005. Washington, DC: 2005.

Cummins, J. David. "Convergence in Wholesale Financial Services: Reinsurance and Investment Banking.” Geneva Papers on Risk and Insurance, April 2005, 30(2), pp. 187-222.

Cummins, J. David and Danzon, Patricia M. "Price Shocks and Capital Flows in Liability Insurance.” Journal of Financial Intermediation, January 1997, 6(1), pp. 3-38.

Cummins, J. David and Doherty, Neil A. "Capitalization of the Property-Liability Insurance Industry: Overview." Journal of Financial Services Research, February-April 2002, 21(1/2), pp. 5-14.

Cummins, J. David; Doherty, Neil A. and Lo, Anita. "Can Insurers Pay for the 'Big One'? Measuring the Capacity of the Insurance Market to Respond to Catastrophe Losses." Journal of Banking and Finance, March 2002, 26(2/3), pp. 557-83.

Cummins, J. David; Lalonde, David and Phillips, Richard D. "The Basis Risk of Catastrophic-Loss Index Securities." Journal of Financial Economics, June 2004, 71(1), pp. 77-111.

Cummins, J. David and Nini, Gregory. “Optimal Capital Utilization by Financial Firms: Evidence from the Property-Liability Insurance Industry." Journal of Financial Services Research, FebruaryApril 2002, 21(1/2), pp. 15-53.

Cummins, J. David and Weiss, Mary A. "The Global Market for Reinsurance: Consolidation, Capacity, and Efficiency." Brookings-Wharton Papers on Financial Services, 2000, pp. 159-209.

Daniels, Ronald J.; Kettl, Donald F. and Kunreuther, Howard. On Risk and Disaster: Lessons from Hurricane Katrina. Philadelphia, PA: University of Pennsylvania Press, 2006. 
Ericson, Richard V. and Doyle, Aaron. "Catastrophe Risk, Insurance, and Terrorism." Economy and Society, May 2004, 33(2), pp. 135-73.

Freeman, Paul K. and Scott, Kathryn. "Comparative Analysis of Large Scale Catastrophe Compensation Schemes," in Catastrophe Risks and Insurance. Paris: OECD Publishing, 2005.

Froot, Kenneth A. "The Market for Catastrophe Risk: A Clinical Examination." Journal of Financial Economics, May/June 2001, 60(2/3), pp. 529-71.

Grace, Martin F.; Klein, Robert W. and Liu, Zhiyong. "Mother Nature on the Rampage: Implications for Insurance Markets." Working paper, Georgia State University, 2006.

Guy Carpenter. The World Catastrophe Reinsurance Market. New York: 2005.

Harrington, Scott E. and Niehaus, Greg. "Capital, Corporate Income Taxes, and Catastrophe Insurance." Journal of Financial Intermediation, 12(4), pp. 365-89.

Hartwig, Robert P. "Hurricane Season of 2005: Impacts on US P/C Insurance Markets in 2006 and Beyond." Powerpoint presentation. New York: Insurance Information Institute, 2005.

Hillman, Richard J. Terrorism Insurance: Rising Uninsured Exposure to Attacks Heightens Potential Economic Vulnerabilities. GAO-02-472T.

Washington, DC: U.S. General Accounting Office, 2002.

Hubbard, R. Glenn and Deal, Bruce. The Economic Effects of Federal Participation in Terrorism Risk. Washington, DC: The Analysis Group, 2004.

Jaffee, Dwight M. "The Role of the Government in the Coverage of Terrorism Risks," in Policy Issues in Insurance: Terrorism Risk Insurance in OECD Countries. Paris: OECD Publishing, 2005.

Jaffee, Dwight M. and Russell, Thomas "Catastrophe Insurance, Capital Markets, and Uninsurable Risks." Journal of Risk and Insurance, June 1997, 64(2), pp. 205-30.
Jaffee, Dwight M. and Russell, Thomas. "Markets Under Stress: The Case of Extreme Event Insurance," in Richard Arnott et al., eds., Economics for an Imperfect World: Essays in Honor of Joseph E. Stiglitz. Cambridge, MA: MIT Press, 2003.

Jenkins, William O. Jr. Federal Emergency Management Agency: Challenges Facing the National Flood Insurance Program. GAO-06-174T. Washington, DC: U.S. General Accounting Office, 2006.

Kunreuther, Howard. "Mitigating Disaster Losses Through Insurance." Journal of Risk and Uncertainty, May 1996, 12(2/3), pp. 171-87.

Kunreuther, Howard and Michel-Kerjan, Erwann. "Challenges for Terrorism Risk Insurance in the United States." Journal of Economic Perspectives, Fall 2004, 18(4), pp. 201-14.

Kunreuther, Howard and Michel-Kerjan, Erwann. "Looking Beyond TRIA: A Clinical Examination of Potential Terrorism Loss Sharing." Working paper, The Wharton School, University of Pennsylvania, 2006.

Kunreuther, Howard; Michel-Kerjan, Erwann and Porter, Beverly. "Assessing, Managing, and Financing Extreme Events: Dealing with Terrorism." NBER Working Paper No. 10179, National Bureau of Economic Research, 2003.

Lakdawalla, Darius and Zanjani, George. "Insurance, Self-Protection, and the Economics of Terrorism." NBER Working Paper No. 9215, National Bureau of Economic Research, 2002.

Lane Financial. The 2005 Review of the Insurance Securitization Market: GAME ON! Wilmette, IL: 2005.

Lewis, Christopher M. and Murdock, Kevin C. "Alternative Means of Redistributing Catastrophic Risk in a National Risk-Management System," in Kenneth A. Froot, ed., The Financing of Catastrophe Risk. Chicago: University of Chicago Press, 1999.

Litzenberger, Robert H.; Beaglehole, David R. and Reynolds, Craig E. "Assessing Catastrophe 


\section{Cummins}

Reinsurance-Linked Securities as a New Asset Class." Journal of Portfolio Management, December 1996, 23(Special Issue), pp. 76-86.

Marsh. Marketwatch: Property Terrorism Insurance 2004. New York: 2004.

Marsh. Marketwatch: Terrorism Insurance 2005. New York: 2005a.

Marsh. Marketwatch: Terrorism Insurance 2005: Highlights of the TRIA Extension. New York: 2005b.

McDonnell, Enda. "Industry Loss Warranties," in Morton Lane, ed., Alternative Risk Strategies. London: Risk Water Group, 2002.

Michel-Kerjan, Erwann and Pedell, Burkhard. "Terrorism Risk Coverage in the Post-9/11 Era: A Comparison of New Public-Private Partnerships in France, Germany, and the U.S." Geneva Papers on Risk and Insurance, 2005, 30(1), pp. 144-70.

Mortgage Bankers Association. Study of Terrorism Insurance, TRIA and the "Make-Available" Provision. Washington, DC: 2004.

Moss, David A. "Courting Disaster? The Transformation of Federal Disaster Policy Since 1803," in Kenneth Froot, ed., The Financing of Catastrophe Risk. Chicago: University of Chicago Press, 1999.

Organisation for Economic Co-operation and Development. "Catastrophic Risks and Insurance." OECD Policy Issues in Insurance. No. 8. Paris: 2005a.

Organisation for Economic Co-operation and Development. "Terrorism Risk Insurance in OECD Countries.” OECD Policy Issues in Insurance. No. 9. Paris: 2005b.

Pollner, John M. "Managing Catastrophic Disaster Risks Using Alternative Risk Financing and Pooled Insurance Structures.” Technical Paper No. 495, World Bank, 2001.

PricewaterhouseCoopers. California Earthquake Authority: Report on Audits of Financial Statements for the Years Ended December 31, 2004 and 2003. Sacramento, CA: 2005.

Risk Management Solutions. What If the 1923 Earthquake Strikes Again? A Five-Prefecture Tokyo Region Scenario. Menlo Park, CA: 1995.

Rothschild, Michael and Stiglitz, Joseph E. "Equilibrium in Competitive Insurance Markets: An Essay on the Economics of Imperfect Information." Quarterly Journal of Economics, November 1976, 90(4), pp. 630-49.

Standard and Poor's. Global Reinsurance Highlights. 2004 Ed. New York: 2004.

Standard and Poor's. Global Reinsurance Highlights. 2005 Ed. New York: 2005.

Stigler, George J. “The Theory of Economic Regulation.” Bell Journal, 1971, 2(1), pp. 3-21.

Swiss Re. "Capital Market Innovation in the Insurance Industry.” Sigma, 2001, 3.

Swiss Re. "Natural Catastrophes and Man-Made Disasters in 2004: More Than 300,000 Fatalities, Record Insured Losses.” Sigma, 2005a, (1).

Swiss Re. "Innovating to Insure the Uninsurable." Sigma, 2005b, (4).

Swiss Re. "Natural Catastrophes and Man-Made Disasters 2005: High Earthquake Casualties, New Dimension in Windstorm Losses." Sigma, 2006, (2).

U.S. Congress. Terrorism Risk Insurance Act of 2002. H.R. 3210. Washington, DC: GPO, 2002.

U.S. Department of the Treasury, Office of Economic Policy. Assessment: The Terrorism Risk Insurance Act of 2002. Washington, DC: 2005.

U.S. General Accounting Office. Terrorism Insurance: Implementation of the Terrorism Risk Insurance Act of 2002. GAO-04-307. Washington, DC: 2004.

U.S. General Accounting Office. Catastrophe Risk: U.S. and European Approaches to Insure Natural Catastrophes and Terrorism Risk. GAO-05-199. Washington, DC: 2005. 
Wharton Risk Management and Decision Processes Center. TRIA and Beyond: Terrorism Risk

Financing in the U.S. Philadelphia, PA: Wharton School, University of Pennsylvania, 2005.

Winter, Ralph A. "The Dynamics of Competitive Insurance Markets." Journal of Financial

Intermediation, September 1994, 3(4), pp. 379-415. 
